RODOLFO TSUNETAKA TAMANAHA

TRIBUTAÇÃO E ECONOMIA DIGITAL: ANÁLISE DO TRATAMENTO TRIBUTÁRIO DOS RENDIMENTOS DA COMPUTAÇÃO EM NUVEM

TESE DE DOUTORADO

ORIENTADOR: PROFESSOR DOUTOR ROBERTO QUIROGA MOSQUERA

UNIVERSIDADE DE SÃO PAULO

FACULDADE DE DIREITO

São Paulo-SP 


\title{
TRIBUTAÇÃO E ECONOMIA DIGITAL: ANÁLISE DO TRATAMENTO TRIBUTÁRIO DOS RENDIMENTOS DA COMPUTAÇÃO EM NUVEM
}

\begin{abstract}
Tese apresentada à Banca Examinadora do Programa de Pós-Graduação de Direito, da Faculdade de Direito da Universidade de São Paulo, como exigência parcial para obtenção do título de Doutor em Direito, na área de concentração Direito Econômico, Financeiro e Tributário, sob orientação do Professor Doutor Roberto Quiroga Mosquera.
\end{abstract}

\section{UNIVERSIDADE DE SÃO PAULO \\ FACULDADE DE DIREITO}

São Paulo-SP 
Catalogação da Publicação

Serviço de Biblioteca e Documentação

Faculdade de Direito da Universidade de São Paulo

Tamanaha, Rodolfo Tsunetaka

Tributação e economia digital: análise do tratamento tributário dos rendimentos da computação em nuvem /Rodolfo Tsunetaka Tamanaha ; orientador: Roberto Quiroga Mosquera - São Paulo, 2017.

Tese (Doutorado - Programa de Pós-Graduação em Direito Econômico, Financeiro e Tributário) - Faculdade de Direito, Universidade de São Paulo, 2017.

1. Direito tributário. 2. Economia digital. 3. Computação em nuvem. 4. Tributação de não residente. 5. Software. 
Banca Examinadora 
Dedico este trabalho a Deus, à Aictyr, à Sofia e aos meus pais. 


\section{AGRADECIMENTOS}

Agradeço ao meu orientador, Professor Roberto Quiroga Mosquera, pela confiança, orientações e apoio durante o desenvolvimento desta tese.

À família, amigos e colegas de trabalho, por conta das inúmeras ausências que a elaboração do trabalho exigiu.

Às bibliotecárias do Instituto Brasileiro de Direito Tributário (IBDT) e de diversas bibliotecas na Esplanada dos Ministérios, que muito me auxiliaram na pesquisa. 


\section{RESUMO}

TAMANAHA, Rodolfo Tsunetaka. Tributação e economia digital: análise do tratamento tributário dos rendimentos da computação em nuvem. 2017. 307 f. Doutorado - Faculdade de Direito, Universidade de São Paulo, São Paulo, 15.5.2017.

A presente tese de doutorado versa sobre o tratamento tributário dos rendimentos da computação em nuvem sob a perspectiva do regime interno e convencional do Imposto de Renda (IR). No primeiro capítulo, é abordado o fenômeno contemporâneo da digitalização da economia. No segundo capítulo, realiza-se uma análise jurídica dos bens digitais que não necessitam de suporte físico. No terceiro e quarto capítulos, a análise é direcionada, respectivamente, para os aspectos técnicos e jurídicos da computação em nuvem. O capítulo quinto é dedicado a enfrentar a temática da interação entre o direito tributário e o direito privado, de forma a aferir a relação que deve existir entre as categorias e os institutos de direito privado e o direito tributário, em um contexto de tributação de novas tecnologias. No capítulo sexto, realiza-se uma análise do ponto de vista obrigacional das espécies de contratos de computação em nuvem. O capítulo sétimo inicia-se com um estudo sobre as bases da tributação internacional, tendo em conta os efeitos decorrentes da economia digital. No capítulo oitavo, a tese inicia a investigação com o debate sobre a tributação dos rendimentos do não residente no direito brasileiro, para, em seguida, debater a tributação específica dos rendimentos do software. No capítulo nono, analisam-se os principais aspectos dos acordos contra a dupla tributação, além de enfrentar-se o tema do tratamento tributário dos rendimentos do software, no âmbito convencional. Por fim, o décimo capítulo apresenta o posicionamento recente das autoridades fiscais sobre a qualificação dos rendimentos da computação em nuvem, para finalizar a tese com uma proposta de tratamento tributário dos rendimentos das três espécies de computação em nuvem e dos contratos mistos de nuvem.

Palavras-chave: Direito tributário. Economia digital. Computação em nuvem. Tributação de não residente. Software. 


\section{ABSTRACT}

TAMANAHA, Rodolfo Tsunetaka. Taxation and digital economy: analysis of the tax treatment of income from cloud computing. 2017. 307 f. Doctoral Thesis - Faculty of Law, University of São Paulo, São Paulo, 05.15.2017

This thesis deals with the tax treatment of cloud computing income from the perspective of the internal and conventional Income Tax (IR) regimes. In the first chapter, the contemporary phenomenon of the digitalization of the economy is approached. In the second chapter, a legal analysis of digital goods that do not require physical support is carried out. In the third and fourth chapters, the analysis is directed, respectively, to the technical and legal aspects of cloud computing. The fifth chapter deals with the interaction between tax law and private law, in order to assess the relationship that should exist between the categories and institutes of private law and tax law, in a context of taxation of new technologies. In chapter six, an analysis is performed from the obligatory point of view of the species of cloud computing contracts. The seventh chapter begins with a study on the bases of international taxation, taking into account the effects of the digital economy. In the eighth chapter, the thesis begins the investigation with the debate on the taxation of the income of the non-resident in the Brazilian law, and then to discuss the specific taxation of income from software. In the ninth chapter, the main aspects of the agreements against double taxation are analyzed, as well as the tax treatment of software revenues, in the conventional scope. Finally, the tenth chapter presents the recent position of tax authorities on the qualification of cloud computing consideration, to finalize the thesis with a proposal for tax treatment of the income of the three species of cloud computing and also mixed cloud contracts.

Keywords: Tax law. Digital economy. Cloud computing. Non-resident taxation. Software. 


\section{RÉSUMÉE}

TAMANAHA, Rodolfo Tsunetaka. Fiscalité et économie numérique : analyse du traitement fiscal des revenus de l'informatique en nuage. 307 pages. Doctorat - Faculté de Droit, Université de São Paulo, São Paulo, 15.5.2017.

Cette thèse de doctorat a pour objet le traitement fiscal des revenus provenant de l'informatique en nuage sous la perspective du régime interne et conventionnel de l'impôt sur le revenu (IR en portugais). Dans le premier chapitre, nous abordons le phénomène contemporain de la numérisation de l'économie. Dans le second chapitre, nous réalisons une analyse juridique des biens numériques qui n'ont pas besoin de support physique. Dans le troisième et quatrième chapitres, l'analyse se tourne respectivement vers les aspects techniques et juridiques de l'informatique en nuage. Le chapitre cinq se consacre à aborder la thématique de l'interaction entre le droit tributaire et le droit privé, de façon à mesurer la relation qui doit exister entre les catégories et les instituts de droit privé et le droit tributaire, dans un contexte d'imposition des nouvelles technologies. Dans le chapitre six, nous réalisons une analyse du point de vue obligationnel des types de contrats d'informatique en nuage. Le septième chapitre commence avec une étude sur les bases de l'imposition internationale, en prenant en compte les effets découlant de l'économie numérique. Dans le huitième chapitre, la thèse commence l'investigation avec la discussion sur l'imposition des revenus du non résident dans le droit brésilien, pour débattre ensuite l'imposition spécifique des revenus du software. Dans le neuvième chapitre, nous analysons les principaux aspects des accords contre la double imposition, en plus d'aborder le thème du traitement tributaire des revenus du software, dans le cadre conventionnel. Enfin, le dixième chapitre présente la position récente des autorités fiscales sur la qualification des revenus de l'informatique en nuage, pour finaliser la thèse avec une proposition de traitement fiscal des revenus des trois types d'informatique en nuage et des contrats mixtes proposés par cette activité.

Mots-clefs: Droit tributaire. Économie numérique. Informatique en nuage. Imposition de non résidents. Software. 


\section{LISTA DE SIGLAS}

ANATEL - Agência Nacional de Telecomunicações

BEPS - Erosão da Base Tributária e Transferência de Lucros (Base Erosion and Profit Shifting)

CDN - Content Delivery Network

CGI.br - Comitê Gestor da Internet no Brasil

CNPq - Conselho Nacional de Desenvolvimento Científico e Tecnológico

GATS - Acordo Geral sobre Comércio de Serviços

IaaS - Infraestrutura como um Serviço (Infrastructure as a Service)

IAB - Conselho de Arquitetura da Internet (Internet Architecture Board)

ICANN - Internet Corporation for Names and Numbers

ICMS - Imposto sobre Circulação de Mercadorias e Comunicação

IETF - Força Tarefa de Engenharia da Internet

IP - Protocolo de Interconexão (Internet Protocol)

IR - Imposto de Renda

IRRF - Imposto de Renda Retido na Fonte

ISOC - Sociedade da Internet (Internet Society)

ISSQN - Imposto Sobre Serviços de Qualquer Natureza

ITU - União Internacional de Telecomunicações (International Telecommunication Union)

NIST - Instituto Nacional de Padrões e Tecnologia (National Institute of Standards and Technology)

OCDE - Organização para a Cooperação e Desenvolvimento Econômico

OMC - Organização Mundial do Comércio (World Trade Organization - WTO)

OMPI - Organização Mundial da Propriedade Intelectual

ONU - Organização das Nações Unidas

PaaS - Plataforma como um Serviço (Plataform as a Service

RAM - Memória volátil (Random Access Memory)

RNP - Rede Nacional de Pesquisa

$\mathrm{SaaS}$ - Software como um Serviço (Software as a Service)

SMP - Serviço Móvel Pessoal

TCP - Protocolo de Controle de Transmissão (Transmission Control Protocol)

TIC - Tecnologias da Informação e Comunicação

TRIPS - Acordo sobre Aspectos dos Direitos de Propriedade Intelectual Relacionados ao Comércio 


\section{SUMÁRIO}

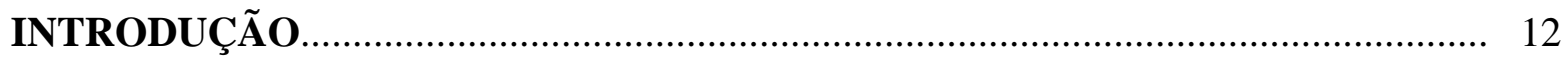

PARTE I

ECONOMIA DIGITAL E COMPUTAÇÃO EM NUVEM........................................ 19

1 DIGITALIZAÇÃO DA ECONOMIA ………………………………........ 19

1.1 Evolução do setor de Tecnologia da Informação e Comunicação........................... 19

1.1.1 Computação........................................................................................ 20

1.1.2 Telecomunicações................................................................................ 23

$1.1 .3 \quad$ Internet.

1.1.4 Convergência da base tecnológica............................................................... 31

$1.2 \quad$ Economia digital e os novos modelos de negócios................................................ 33

1.2.1 Noções fundamentais............................................................................. 34

1.2.2 Comércio eletrônico........................................................................................ 39

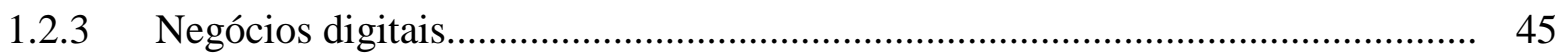

2 CARACTERIZAÇÃO DOS BENS DIGITAIS........................................... 50

$2.1 \quad$ Regime jurídico de proteção.................................................................... 53

2.2 Regime de exploração econômica.................................................................. 56

$2.3 \quad$ Meios de transmissão................................................................................... 61

3 ASPECTOS TÉCNICOS DA COMPUTAÇÃO EM NUVEM....................... 68

$3.1 \quad$ Considerações preliminares........................................................................ 68

3.2 Elementos técnicos da computação em nuvem................................................... 73

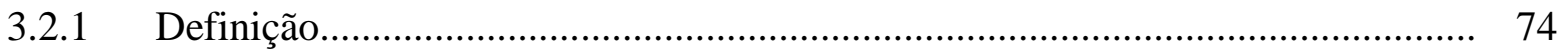

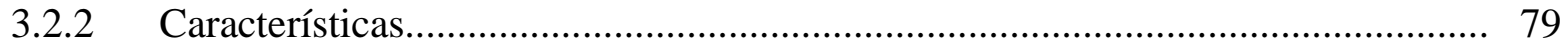

3.2.3 Espécies................................................................................... 80

3.2.4 Modelos de implantação.................................................................................... 84

3.2.5 Participantes.................................................................................. 86

4 ASPECTOS JURÍDICOS DA COMPUTAÇÃO EM NUVEM....................... 87

4.1 Aproximação inicial: outsourcing de TI......................................................... 87

4.2 Estruturação jurídica da computação em nuvem.................................................. 92

4.3 Formatação contratual da computação em nuvem.................................................. 96

4.3.1 Características gerais................................................................................ 97

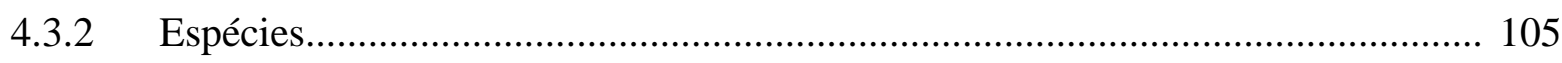

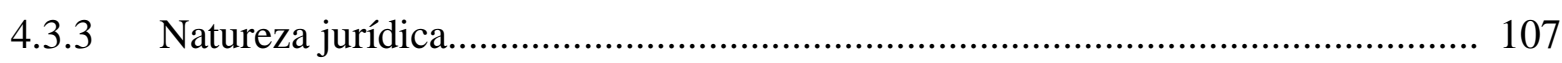

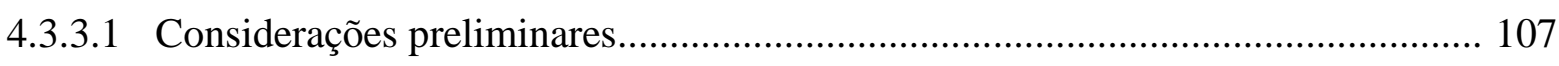

4.3.3.2 Principais conteúdos obrigacionais............................................................... 110 


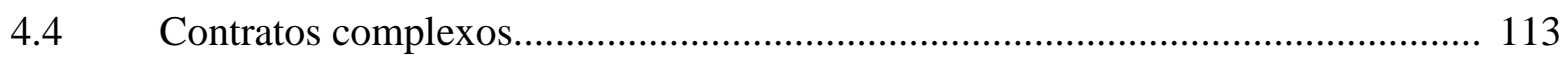

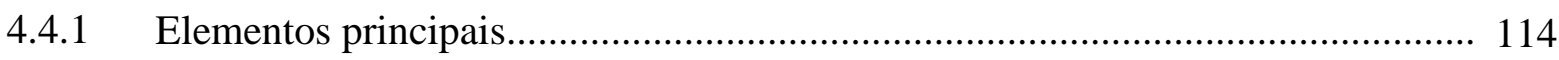

4.4.2 Critérios para diferenciar as obrigações....................................................... 117

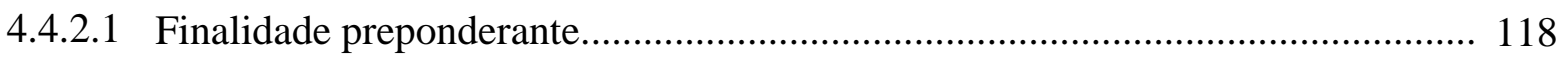

4.4.2.2 Operações mistas: análise da jurisprudência..................................................... 122

4.4.3 Parâmetros de análise dos contratos de computação em nuvem........................... 126

5 INTERAÇÃO ENTRE O DIREITO TRIBUTÁRIO E O DIREITO

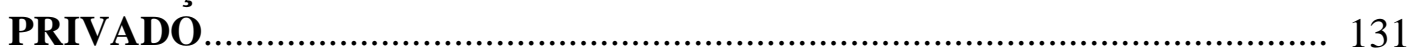

5.1 Conceitos de direito privado e autonomia do direito tributário........................... 132

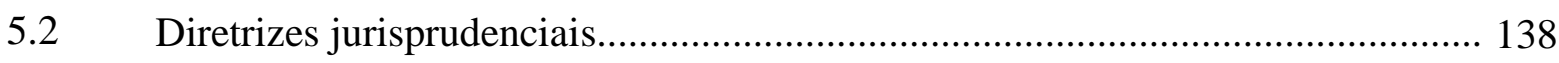

5.3 Conclusão: (im)permeabilidade do direito tributário........................................ 141

6 ANÁLISE DAS ESPÉCIES DE CONTRATOS DE COMPUTAÇÃO EM

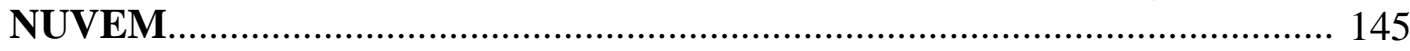

6.1 Análise preliminar: licença de uso de software ............................................... 145

6.2 Contrato de Software como um Serviço - Software as a Service (SaaS)............ 149

6.3 Contrato de Plataforma como um Serviço - Plataform as a Service (PaaS)......... 150

6.4 Contrato de Infraestrutura como um Serviço - Infrastructure as a Service (IaaS) 151

6.5 Contrato misto de computação em nuvem........................................................ 153

PARTE II

TRIBUTAÇÃO DOS RENDIMENTOS DA COMPUTAÇÃO EM NUVEM 154

7 BASES DA TRIBUTAÇÃO INTERNACIONAL E ECONOMIA

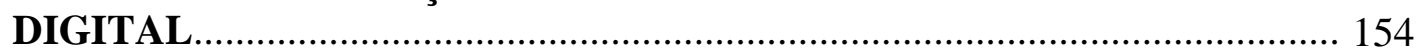

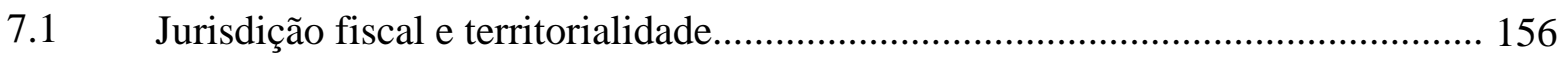

7.2 Substantive jurisdiction e enforcement jurisdiction ............................. 160

7.3 Universalidade e os princípios da residência e da fonte...................................... 166

7.4 Crise dos elementos de conexão................................................................... 178

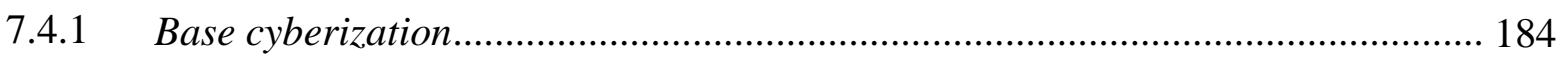

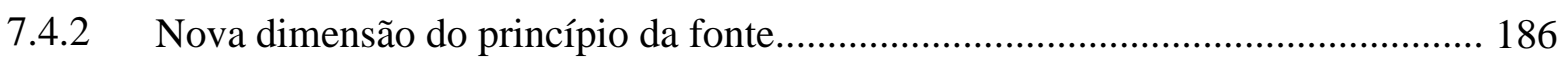

8 TRIBUTAÇÃO DOS RENDIMENTOS DO NÃO RESIDENTE NO DIREITO BRASILEIRO

8.1 Regimes aplicáveis à tributação do não residente e a relevância da presença

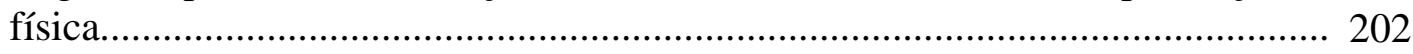

8.2 Tratamento tributário interno dos rendimentos produzidos por não residentes.... 205

8.3 Tributação dos rendimentos específicos de software ........................................ 213

8.3.1 Aportes da jurisprudência dos Tribunais Superiores.......................................... 213

8.3.2 Caracterização dos rendimentos de software .................................................... 221

S.3.3 Software e transferência de tecnologia............................................................. 229 
9 TRIBUTAÇÃO DO SOFTWARE NOS ACORDOS INTERNACIONAIS EM MATÉRIA TRIBUTÁRIA

9.1 Noções sobre dupla tributação e acordos contra a dupla tributação..................... 240

9.2 Tratamento tributário dos rendimentos do software no plano internacional......... 248

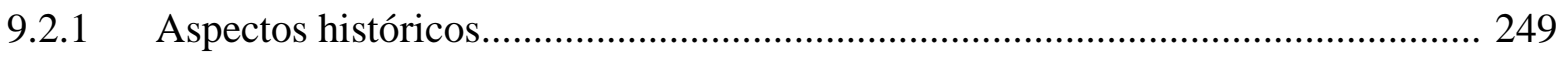

9.2.2 Regime jurídico de proteção do software ........................................................... 251

9.2.3 Exploração econômica do software ................................................................... 254

9.3 Qualificação dos rendimentos envolvendo software ......................................... 257

10 TRATAMENTO TRIBUTÁRIO DOS RENDIMENTOS DA COMPUTAÇÃO EM NUVEM.............................................................. 262

10.1 Qualificação dos Rendimentos da Computação em Nuvem: Posição do Fisco.... 262

10.2 Tratamento tributário dos rendimentos da Infraestrutura como um Serviço Infrastructure as a Service (IaaS) ............................................................... 266

10.3 Tratamento tributário dos rendimentos da Plataforma como um Serviço Plataform as a Service (PaaS) ........................................................................ 267

10.4 Tratamento tributário dos rendimentos do Software como um Serviço Software as a Service (SaaS) ........................................................................ 268

10.5 Contrato misto de computação em nuvem........................................................ 269

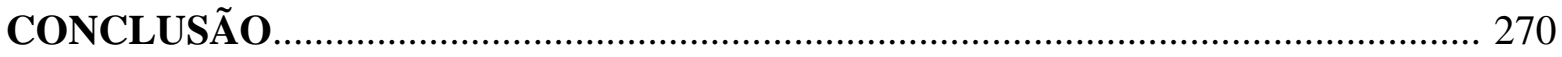

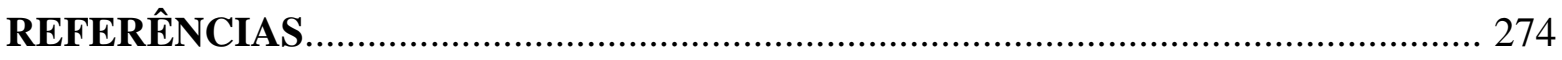




\section{INTRODUÇÃO}

A economia digital ${ }^{1,2}$ representa a faceta contemporânea da economia baseada na utilização intensa das novas Tecnologias da Informação e Comunicação (TIC), na coleta e tratamento de dados e no emprego de intangíveis em larga escala que, a partir da rede mundial de computadores, tem impulsionado o surgimento de novos modelos de negócios ${ }^{3}$. Com o progresso tecnológico acentuado dos últimos anos, ocorreu ampla disseminação dos recursos de TIC, a baixo custo, entre diversos atores do cenário econômico global ${ }^{4}$. De multinacionais tradicionais, passando pelas novas corporações digitais e startups, até alcançar modelos de negócios em que um grupo reduzido de indivíduos espalhados em diversas partes do mundo gerem uma "micromultinacional", as novas tecnologias

\footnotetext{
${ }^{1}$ Conforme esclarece Daniel Piazolo, algumas expressões foram cunhadas nos últimos tempos para tentar capturar a essência das consequências econômicas advindas do uso crescente de novas tecnologias da informação e comunicação e das redes de computadores interligados para realizar transações e promover o comércio de bens e serviços em escala global. As principais são: "economia da informação", "economia do conhecimento", "economia virtual" e "economia digital" (PIAZOLO, Daniel. The New Economy and the International Regulatory Framework. Kiel Working Paper n. 1030. Kiel Institute of World Economics. Kiel, mar. 2001). De forma irônica, Walter Hellerstein afirma a respeito da definição de economia digital que "it suffices to paraphrase US Supreme Court Justice Potter Stewart's observation about pornography although we may not be able to define it, "we know it when we see it" (HELLERSTEIN, Walter. Jurisdiction to Tax in the Digital Economy: Permanent and Other Establishments. Bulletin for International Taxation. v. 68, n. 6/7. Amsterdam: IBFD. p. 346-351. junho/julho de 2014). Vale mencionar, também, a referência ao livro "The Digital Economy: Promise and Peril in the Age of Networked Intelligence", de Don Tapscott, que exerceu influência na disseminação da expressão, conforme citado por BRAUNER, Yariv; BAEZ, Andrés. Withholding Taxes in the Service of BEPS Action 1: Address the Tax Challenges of Digital Economy. IBFD White Papers. Amsterdam: IBFD. p. 1-33 [11]. 2015.

${ }^{2}$ Neste trabalho, optou-se por adotar referida expressão pelo fato dela ser empregada no plano de ação da força-tarefa constituída pela Organização para Cooperação e Desenvolvimento Econômico - OCDE, em 2013, para discutir alterações na tributação internacional diante dos desafios fiscais decorrentes da digitalização da economia e da problemática da erosão da base tributária do imposto de renda (Cf. OECD. Action Plan on Base Erosion and Profit Shifting. Paris: OECD Publishing, 2013, p. 10).

3 "The application of big data, new algorithms, and cloud computing will change the nature of work and the structure of the economy" (ZYSMAN, John; KENNEY, Martin. The Next Phase in the Digital Revolution: Platforms, Abundant Computing; Growth and Employment. Berkeley Roundtable on International Economy - BRIE Working Paper n. 2016-3, ago. 2016, grifo nosso. Disponível em: $<$ http://www.brie.berkeley.edu/wp-content/uploads/2015/02/BRIE-working-paper-2016-33.pdf >. Acesso em: 13 set. 2016.

${ }^{4}$ OECD. Addressing the Tax Challenges of the Digital Economy. Action 1 - 2015 Final Report. Paris: OECD Publishing, 2015, p. 36.

5 "At the forefront of this seismic shift in the way jobs are created and economic value added is a new type of company, the micro-multinational. Traditionally, these small, self-starting, service-driven companies would have been described as small- and medium sized enterprises, or SMEs, but thanks to the Internet, the emergence of new business platforms and the increased openness of the global economy, these companies can enter markets with a minimum of bureaucracy and overhead." (METTLER, Ann; WILLIAMS, Anthony D. The Rise of the Micro-Multinational: How Freelancers and Technology-Savvy Start-Ups Are Driving Growth, Jobs and Innovation. The Lisbon Council Policy Brief, 2011 - g. n.). Conferir, também: STEPANEK, Marcia. Micro-Multinationals Rising. Stanford Social Innovation Review, 14 mai. 2010. Disponível em: <http://ssir.org/articles/entry/micro-multinationals_rising>. Acesso em: 13 mar. 2016.
} 
disseminaram-se, de forma ampla, pelos diversos setores econômicos, potencializando a produtividade, possibilitando a expansão da atividade econômica para mercados globais e reduzindo, sensivelmente, os custos operacionais.

Nesse contexto de inovação constante das atividades empresariais por conta dos avanços de base tecnológica, avultam as dificuldades atinentes à definição da natureza jurídica das operações econômicas envolvidas ${ }^{6}$, o que é indispensável para o delineamento e a aplicação do arcabouço tributário ${ }^{7}$. Exemplo dessa nova realidade é a transição que se verifica nas corporações, que deixam de investir nos tradicionais sistemas locais (onpremises) de TIC, para aderir à computação em nuvem ${ }^{8}$. Segundo a consultoria Gartner, o mercado emergente da computação em nuvem compreendeu transações comerciais da ordem de 200 bilhões de dólares somente em $2016^{9}$.

A computação em nuvem - ou, simplesmente, "nuvem" - é a entrega de recursos computacionais de forma automática e escalável pela Internet $^{10}$, que tem modificado de modo fundamental a maneira como as funcionalidades de TIC são desenvolvidas, implementadas e administradas pelas empresas ${ }^{11}$. A partir do refinamento de recursos de tecnologia existentes, a nuvem vale-se principalmente de recursos de software, além de computadores e de servidores espalhados pelo mundo, para disponibilizar aplicações, plataformas e espaços de armazenamento digital, que podem ser acessados de qualquer localidade pela Internet.

Entretanto, as transações econômicas envolvendo a computação em nuvem diferenciam-se, em vários aspectos, do provisionamento tradicional de recursos de TIC, o

\footnotetext{
6 "It is an age-old debate. Does law aid or hinder innovation? New technologies present new opportunities and new challenges for regulation." (LOBEL, Orly. The Law of the Platform. San Diego Legal Studies, Research Paper n. 16-212, mar. 2016, p. 22).

7 GRECO, Marco Aurélio. Sobre o Futuro da Tributação: a Figura dos Intangíveis. Revista Direito Tributário Atual n. 25, São Paulo: Dialética, v. 25, 2011, p. 108-120 [117].

${ }^{8}$ SAUER, Rich. Conquistando Confiança e Compliance na Nuvem. International In-house Counsel Journal. vol. 09. n. 36. 2016.

${ }^{9}$ GAUDIN, Sharon. Global public cloud market expected to hit \$204B in 2016. ComputerWorld, jan./2016. Disponível em: <http://www.computerworld.com/article/3026396/cloud-computing/global-public-cloudmarket-expected-to-hit-204b-in-2016.html>. Acesso em: 4 ago. 2016.

10 Adota-se neste trabalho o termo Internet com "i" maiúsculo, em consonância com a doutrina especializada: "Neste trabalho, a expressão Internet será grafada com 'i' maiúsculo, referente a rede global de computadores conectados entre si. É oportuno recordar que internet com 'i' minúsculo é a contração de interconnected network (rede interconectada), expressão que pode ser usada para se referir a redes de computadores privadas interligadas sem qualquer relação com a Internet global. Em outras palavras, a Internet é uma internet, mas a reciproca não é verdadeira" (LEONARDI, Marcel. Tutela e Privacidade na Internet. São Paulo: Saraiva, 2011, p. 23, nota de rodapé 1). Portanto, a Internet compreende um conjunto de redes abertas e interconectadas de comunicação em escala mundial, o que a diferencia de redes de comunicação fechadas, como o Electronic Data Interchange - EDI.

${ }^{11}$ BAL, Aleksandra. The Sky's the Limit - Cloud-Based Services in an International Perspective. Bulletin for International Taxation. n. 9. p. 515-521 [515]. set./. 2014.
} 
que ocasiona consequências no plano tributário que não podem ser ignoradas. Pelo fato de suas atividades ocorrerem em sua quase integralidade no mundo digital, a nuvem potencializa as dificuldades referentes à alocação da competência tributária entre Estados, uma vez que elimina sensivelmente a necessidade de presença física no território em que o rendimento é produzido.

No entanto, o maior desafio do ponto de vista tributário coloca-se no tocante à qualificação dos rendimentos decorrentes das transações que podem ocorrer no bojo de um contrato de computação em nuvem. Dada a natureza imaterial das atividades desenvolvidas, o intérprete encontra muitas incertezas para definir o tipo de transação realizada, o que dificulta determinar as consequências tributárias pertinentes. Por outro lado, há de se considerar que o setor de TIC e a própria computação em nuvem estão estruturados a partir de programas de computador, o que representa um passo inicial para se compreender como se deve se dar o tratamento tributário das atividades econômicas empreendidas.

Sendo esse o contexto, o objeto do presente estudo é voltado a analisar o tratamento tributário dos rendimentos de contratos de computação em nuvem, sob a perspectiva do regime interno e convencional do Imposto de Renda (IR). O estudo limitarse-á a investigar os principais aspectos relacionados à tributação do residente no exterior pelo IR, por se tratar de um dos principais tributos quando se fala em negócios internacionais.

Em que pese os estudos nacionais voltados à tributação internacional já contarem com uma produção substanciosa ${ }^{12}$, o enfoque específico voltado aos negócios relacionados às novas tecnologias - em que a computação em nuvem se destacada pela importância econômica e complexidade do modelo de negócios -, ainda é pouco explorado no Brasil. A produção existente é de qualidade, mas são poucos os autores que se dedicaram de forma aprofundada sobre a matéria. Portanto, trata-se de temática que deve ser explorada, tendo em vista que a revolução tecnológica em curso tem ocasionado mudança radical no contexto econômico e social, o que, por sua vez, demanda reavaliação do conteúdo e alcance dos referenciais jurídico-tributários clássicos ${ }^{13}$.

\footnotetext{
${ }^{12}$ Como faz prova toda a extensa bibliografia nacional de qualidade utilizada neste estudo.

13 “[...] a Revolução Digital trará para esta última [ciência jurídica] impactos tão ou mais consideráveis do que aqueles que foram ocasionados pela Revolução Industrial” (LUCCA, Newton. Tributação e Internet. In: MARTINS, Ives Gandra da Silva (Coord.). Tributação na Internet. São Paulo: Revista dos Tribunais, 2001, p. $131-$ g. n.).
} 
Em vista disso, a tese tocará alguns temas em caráter dissertativo, apenas como apoio à investigação científica, mas sempre com a preocupação de ressaltar as características que desafiam a tributação dos rendimentos. Outros temas serão analisados de forma mais aprofundada, uma vez que se ligam diretamente com o cerne do estudo. Tomando como objeto central da tese a análise do tratamento tributário dos rendimentos da computação em nuvem, buscar-se-á enfrentar as seguintes questões principais: (i) qual a natureza jurídica das operações realizadas no âmbito de um contrato de computação em nuvem e (ii) em que medida os parâmetros para a tributação do software no plano interno e convencional podem ser úteis para avaliar a tributação da computação em nuvem.

Diante da complexidade e da variedade dos recursos oferecidos por esse novo modelo de negócios, a hipótese que se propõe no plano interno é que os valores pagos, creditados, entregues ou remetidos para empresa domiciliada no exterior, em decorrência da contratação de computação em nuvem, não se qualificam apenas como remuneração pela prestação de serviços, podendo assumir diferentes naturezas jurídicas, como pagamento decorrente de aluguel de bem móvel, concessão de direito de uso, licença de uso e mesmo contraprestação decorrente de operação de compra e venda, a depender da espécie de nuvem adotada e das funcionalidades contratadas, o que ocasiona reflexos tributários distintos que precisam ser evidenciados.

Em outras palavras, há a necessidade de se avaliar a natureza jurídica das atividades virtuais afetas à computação em nuvem à luz da legislação interna e da jurisprudência dos Tribunais Superiores, de forma a caracterizar as soluções digitais fornecidas como prestação de serviço - com ou sem transferência de tecnologia e em caráter principal ou acessório -; locação ou compra e venda de um bem (móvel ou virtual); ou, ainda, licenciamento de direito (intelectual). Disso, resta evidente, deduzem-se consequências tributárias distintas, que estão a merecer melhor reflexão.

Por outro lado, é usual que ocorra a contratação de computação em nuvem de empresa provedora residente em país com o qual o Brasil tenha firmado tratado para prevenir a dupla tributação, tendo como referência a Convenção Modelo da Organização para a Cooperação e Desenvolvimento Econômico (OCDE). Por esse motivo, uma investigação dos parâmetros estabelecidos no plano convencional para a tributação do software é necessária, de forma a analisar os rendimentos da computação em nuvem. Sugere-se que referidos rendimentos sejam qualificados, primordialmente, como "lucros da 
empresa", de acordo com o artigo $7^{\circ}$, da referida Convenção Modelo ${ }^{14}$, permitindo a tributação no estado da residência, caso não haja estabelecimento permanente no estado da fonte e, de forma subsidiária, como royalties, em consonância com o artigo $12^{15}$, quando a tributação pode ocorrer no país da fonte ${ }^{16}$. Esta é a hipótese que se apresenta no plano convencional, com base em estudo realizado pela OCDE, em 2001, sobre a caracterização dos rendimentos decorrentes do comércio eletrônico ${ }^{17}$, mas que precisa ser confrontada, tendo em conta as características únicas de modelos de negócios desmaterializados que surgem no contexto da economia digital, como a computação em nuvem.

Uma vez indicado o problema de pesquisa e as hipóteses de investigação, a abordagem metodológica adotada é dogmática, compreendida em suas três dimensões: analítica, empírica e normativa ${ }^{18}$. A dimensão analítica reflete o estudo dos conceitos envolvidos e a relação entre eles, a partir de perspectiva interdisciplinar entre a propriedade intelectual e o direito tributário. A empírica abrange avaliação crítica da doutrina nacional e internacional, assim como da jurisprudência brasileira e dos Comentários oficiais da Convenção Modelo da OCDE. Com base nesses resultados, pretende-se buscar respostas adequadas às indagações formuladas na dimensão normativa, de forma a prescrever a forma como a tributação dos rendimentos da computação em nuvem deve ocorrer.

Em vista disso, o desenvolvimento do estudo ocorrerá da seguinte forma. Como as funcionalidades intangíveis da computação em nuvem encontram-se materializadas em instrumentos contratuais, é relevante discutir aspectos essenciais das categorias obrigacionais que podem corporificar contratos de nuvem, de forma a se deduzir as respectivas consequências tributárias. Por sua vez, o debate envolvendo os aspectos fiscais da computação em nuvem não prescinde de investigação aprofundada sobre a tributação dos bens digitais, i.e., do software, uma vez que inexiste nuvem sem programas

\footnotetext{
14 "Article 7. Profits of an enterprise of a Contracting State shall be taxable only in that State unless the enterprise carries on business in the other Contracting State through a permanent establishment situated therein. If the enterprise carries on business as aforesaid, the profits that are attributable to the permanent establishment in accordance with the provisions of paragraph 2 may be taxed in that other State."

15 "Article 12. Royalties arising in a Contracting State and beneficially owned by a resident of the other Contracting State shall be taxable only in that other State."

${ }^{16}$ Como será discutido na Seção 9, infra, a regra pela Convenção Modelo da OCDE é que a tributação dos royalties ocorra no país da residência, mas diversos Estados, como o Brasil, optam por tributar esse rendimento na fonte.

17 OECD. Tax Treaty Characterization Issues Arising from E-Commerce. Paris: OECD Publishing, 2001.

18 ALEXY, Robert. Teoria dos direitos fundamentais. São Paulo: Malheiros. 2008, p. 33-36.
} 
de computador ${ }^{19}$. Para tanto, realiza-se uma análise crítica da doutrina e jurisprudência nacionais, assim como das propostas de solução presentes nos Comentários oficiais da Convenção Modelo da $\mathrm{OCDE}^{20}$, que tratam da tributação de software. O roteiro da presente tese é composto, além desta seção introdutória, por duas partes, que, por sua vez, são divididas em dez seções, seguida da conclusão. O objetivo da Parte I é contextualizar o surgimento da computação em nuvem, apresentar os seus principais aspectos técnicos e, principalmente, jurídicos, sob a perspectiva da propriedade intelectual e do direito obrigacional, de forma a delimitar os contornos dos principais contratos de computação em nuvem. Sua divisão em seções segue a seguinte ordem:

Na primeira seção, é abordado o fenômeno contemporâneo da digitalização da economia, iniciando-se com uma análise sobre a evolução do setor de tecnologia da informação e comunicação e o surgimento de novos modelos de negócios, cuja desmaterialização atinge tanto os bens que fornecem, quanto à presença física nos territórios em que atuam.

Na segunda seção, realiza-se uma análise jurídica desses bens fornecidos pelos novos modelos de negócios, que não necessitam de suporte físico. Discute-se o regime de proteção e exploração pertinentes, finalizando com uma análise dos seus meios de transmissão.

$\mathrm{Na}$ terceira e quarta seções, a análise é direcionada exclusivamente para os aspectos técnicos e jurídicos da computação em nuvem. Especial atenção é dada para os seus aspectos contratuais, que representam o eixo principal para a avaliação dos núcleos obrigacionais que compõem um contrato de computação em nuvem.

A quinta seção é dedicada a enfrentar a temática da interação entre o direito tributário e o direito privado, de forma a aferir a relação que deve existir entre as categorias e os institutos de direito privado e o direito tributário, em um contexto de tributação de novas tecnologias.

Fechando a Parte I da tese, na sexta seção realiza-se uma análise do ponto de vista obrigacional das espécies de contratos de computação em nuvem, fixando-se naquilo que se entende corresponder ao núcleo obrigacional específico de cada espécie de nuvem.

19 MAZUR, Orly. Taxing the Cloud. California Law Review. California, vol. 103, n. 1, fev. 2015. Disponível em: <http://papers.ssrn.com/sol3/papers.cfm?abstract_id=2419644>. Acesso em: 1ํo abr. 2016.

${ }^{20}$ Os Comentários à Convenção Modelo da OCDE são compreendidos como instrumento complementar de interpretação dos seus dispositivos e têm ganhado muito relevo nos últimos anos, por serem fruto de constantes trabalhos de discussão entre os países membros e observadores (Cf. VOGEL, Klaus. The Influence of the OECD Commentaries on Treaty Interpretation. Bulletin - Tax Treaty Monitor. Amsterdam: IBFD. p. 612-619. dez./2000). 
Em seguida, na Parte II da tese, o estudo avança para a análise da tributação dos rendimentos do não residente, especialmente diante das pressões exercidas sobre os institutos clássicos da tributação internacional por parte dos novos modelos de negócios de base tecnológica. Especial atenção é dada à tributação dos bens digitais, i. e., software, no plano interno e convencional, uma vez que a computação em nuvem é composta, essencialmente, de programas de computador. Ao final, a partir da caracterização dos núcleos obrigacionais dos contratos de nuvem realizada na Parte I, inferem-se as consequências tributárias legítimas à luz do regime interno e convencional do imposto de renda. Essa Parte II é composta por quatro seções, que seguem a seguinte ordem:

A sétima seção inicia a segunda parte da tese com um estudo sobre as bases da tributação internacional, tendo em conta os efeitos decorrentes da economia digital. Analisam-se os eixos clássicos da tributação internacional, sempre tendo em conta uma avaliação sobre a sua (in)adequação diante dos desafios fiscais dos novos modelos de negócios.

Na oitava seção, a tese inicia a investigação com o debate sobre a tributação dos rendimentos do não residente no direito brasileiro, para em seguida debater a tributação específica dos rendimentos do software. Essa análise é complementada pela nona seção, em que, após a análise em caráter dissertativo sobre os principais aspectos dos acordos contra a dupla tributação, enfrenta-se o tema do tratamento tributário dos rendimentos do software no âmbito convencional.

Por fim, a seção dez apresenta o posicionamento recente das autoridades fiscais sobre a qualificação dos rendimentos da computação em nuvem, para finalizar a tese com uma proposta de tratamento tributário dos rendimentos das três espécies de computação em nuvem e dos contratos mistos de nuvem.

Em conclusão, o escopo da presente tese é contribuir com o debate acadêmico sobre a tributação dos rendimentos de novos modelos de negócios surgidos no contexto da economia digital, partindo-se da análise aprofundada da computação em nuvem, que é reconhecida como um desafio do ponto de vista tributário ${ }^{21}$.

21 "Such concerns about Digital Economy taxation seem to be even more relevant for some new business, which have been created in the new technological era; in this perspective, reference can be made - first of all - to cloud computing industry." (PERONA, Costanzo. Tax Challenges of Digital Economy: cloud computing taxation issues and impacts. In: SCHOUERI, Luís Eduardo; BIANCO, João Francisco (Coords.). Estudos de Direito Tributário em Homenagem ao Prof. Gerd Willi Rothmann. São Paulo: Quartier Latin. 2016, p. 545 - g. n.). 


\section{CONCLUSÃO}

Com base em todo o exposto e considerado, deve-se sintetizar as conclusões sobre os principais pontos tratados neste estudo.

A evolução do setor de TIC é um fenômeno recente, que tem gerado um grande impacto sobre as relações sociais e econômicas. Fruto dessa interação entre economia e TIC, a economia digital, marcada pela inovação e fomento à criação de novos modelos de negócios baseados na Internet, apresenta desafios novos para o direito, notadamente para o direito tributário. Isso porque os modelos de negócios digitais possibilitam que as transações econômicas sejam realizadas em grande escala e sem a necessidade de presença física por parte da empresa nos diversos locais do mundo em que estejam os seus consumidores.

Portanto, a desmaterialização dos fatores de produção torna mais complexa a aferição da natureza jurídica dos negócios desenvolvidos, o que demanda uma compreensão mínima de como a tecnologia tem modificado a produção e disponibilização dos produtos e serviços, principalmente dos bens digitais. Estes são compreendidos como programas de computador e arquivos digitais, que prescindem de suporte físico para serem transmitidos e/ou acessados, o que desafia a capacidade do Estado de alcançar as manifestações de capacidade contributiva que se multiplicam na economia digital.

No Brasil e na maior parte dos países, o regime jurídico de proteção dos bens digitais é o direito autoral. Por esse motivo, consideram-se os bens digitais como bens intelectuais móveis e intangíveis, cuja utilização econômica pode ser dar a partir de modalidades de uso que possibilitem a comunicação ao público. Por intermédio do direito de reprodução, os programas de computador podem viabilizar a sua expressão econômica passível de tributação.

Entre os diversos tipos de modelo de negócio que surgiram no contexto da economia digital, tem-se a computação em nuvem, considerada pela doutrina como um desafio do ponto de vista tributário. Muito além da antiga terceirização de TI (outsourcing), a computação em nuvem é entendida como o provisionamento dinâmico, escalável e automático por terceiros, de capacidades sofisticadas de hardware e software, através de uma rede, notadamente pela Internet. Existem três modelos principais de nuvem, identificados a partir da arquitetura das funcionalidades postas à disposição do usuário: a IaaS, a Paas e o SaaS, com características e funcionalidades distintas. 
Por se tratar de um modelo de negócios cujas regras contratuais são determinantes para a sua caracterização, a investigação da formatação contratual da computação em nuvem foi um passo imprescindível para se compreender a natureza dos negócios desenvolvidos. Como a contratação da computação em nuvem invariavelmente abrange mais de uma funcionalidade, fez-se o estudo específico dos principais aspectos dos contratos mistos ou complexos. Nesse particular, buscou-se a identificação de parâmetros de análise na doutrina, jurisprudência e Convenção Modelo da OCDE, o que resultou na adoção de dois critérios: a primeira análise deve verificar se é possível separar os núcleos obrigacionais que integram o contrato misto, de forma a conceder o tratamento tributário individualizado; caso não seja possível, a segunda análise deve buscar identificar, a partir das cláusulas contratuais, qual a finalidade preponderante do ajuste, que dará a tônica ao contrato para todos os fins fiscais.

A isso seguiu-se uma análise sobre a interação entre o direito privado e o direito tributário, a partir de aportes vindos da doutrina e da jurisprudência dos Tribunais Superiores, uma vez que o tratamento tributário dos rendimentos da computação em nuvem está intimamente ligado ao reconhecimento da natureza jurídica das atividades digitais empreendidas. Disso resultou a conclusão de que o intérprete deve privilegiar a adoção de definições e institutos cuja significação esteja consolidada a partir do direito privado, salvo quando a legislação tributária claramente atribuir um novo sentido ao texto normativo.

De posse das premissas fixadas até aquele momento, o passo seguinte seria discernir o núcleo obrigacional de cada espécie de contrato de nuvem. Para tanto, realizouse um estudo preliminar sobre o contrato de licença de uso de software, uma vez que, tanto no caso da computação em nuvem quanto nos demais modelos de negócios digitais, o programa de computador tem papel fundamental. A partir disso, verificou-se que, no caso do contrato de Plataforma como Serviço, sua natureza jurídica assemelha-se a uma concessão de direito de uso de espaço digital; e que, no caso dos contratos de Plataforma como Serviço e Software como Serviço, está a se tratar, em ambos, de cessão parcial de direitos, consubstanciada em uma licença de uso de programas de computador.

Em vista da crescente utilização desses recursos computacionais disponíveis na nuvem para as mais diversas operações de cunho econômico de caráter transnacional (cross-board), o estudo avançou para a análise das bases da tributação internacional. Com isso, foi possível assinalar como os principais elementos que integram o corpo central do 
direito tributário internacional têm lidado com as novas formas de produção de renda advindas da economia digital. Discutiu-se com especial atenção os temas da territorialidade e os elementos de conexão, tendo em conta a preocupação colocada no debate internacional sobre as dificuldades enfrentadas pelos países da fonte dos rendimentos para se apropriar de parte da riqueza produzida pela economia digital. Entre os critérios suscitados pela doutrina nacional e internacional para alinhar a jurisdição de observância com a jurisdição substantiva, a fonte de pagamento permanece como um parâmetro que, particularmente no caso dos modelos de negócios intensamente desmaterializados, sugere soluções satisfatórias.

Em seguida, trazendo as preocupações presentes no debate internacional sobre a tributação das novas tecnologias para o debate nacional, o estudo enfocou a tributação dos rendimentos do não residente à luz do direito brasileiro. Nesse contexto, a análise empreendida cuidou de verificar como o regime interno de tributação dos rendimentos lida com a questão do não residente, principalmente sob a ótica da questão da presença física no território nacional. Pelos limites do estudo, a análise não tocou a complexa temática do estabelecimento permanente, a não ser naquilo que fosse necessário para o debate em andamento. Verificou-se que a legislação brasileira estabeleceu sistemática própria de retenção na fonte dos rendimentos brutos auferidos por não residentes, o que, críticas à parte, encontra-se, em certa medida, alinhada com medidas sugeridas pela doutrina internacional destinadas à tributação dos novos negócios.

Ato contínuo, o estudo centrou a análise nos diversos aspectos atinentes à tributação interna dos rendimentos específicos dos programas de computador, como forma de identificar os parâmetros a serem aplicados à computação em nuvem. A partir da investigação da jurisprudência dos Tribunais Superiores, podem-se obter alguns aportes relevantes. Em regra geral, tem-se que o regime de proteção que regula as relações jurídicas entre fornecedor e usuário de software é o do direito autoral, que dá a tônica às transações digitais, por intermédio de licença de uso que envolve, necessariamente, prestação positiva de dar (direito de uso). No ensejo da análise sobre as espécies de contratos envolvendo programas de computador, avaliou-se se e em que medida o tema da transferência de tecnologia teria relação com a exploração econômica dos bens digitais.

Complementando o estudo feito sobre regime interno, prosseguiu-se com investigação específica acerca do tratamento tributário dos rendimentos de software sob a perspectiva convencional. A partir do delineamento dos principais aspectos dos acordos 
contra a dupla tributação, avaliou-se como a oposição entre fonte e residência se materializada no debate da tributação internacional do software, em que o fator determinante reside na qualificação dos rendimentos produzidos no bojo de operações econômicas que envolvem programas de computador. Entre a qualificação dos rendimentos como royalties ou outros rendimentos, em especial lucros de empresas ou ganhos de capital, demonstrou-se que a análise da natureza jurídica das transações envolvendo bens digitais constitui o elemento fundamental para se aferir as consequências tributárias pertinentes.

Por fim, de posse das premissas fixadas no decorrer do estudo, preliminarmente, realizou-se uma apreciação crítica do posicionamento das autoridades fiscais de alguns atos normativos que tocam o tema da computação em nuvem. Em seguida, efetivou-se uma análise objetiva do tratamento tributário dos rendimentos da computação em nuvem. 


\section{REFERÊNCIAS}

AFTER Moore's Law. The Economist, março de 2016. Disponível em:

<http://www.economist.com/technology-quarterly/2016-03-12/after-moores-law>. Acesso em: 5 abr. 2016.

AGUIAR, Ubiratan Diniz. Solução integrada de outsourcing de infraestrutura de TI. Fórum de Contratação e Gestão Pública, ano 13, n. 147, Belo Horizonte, p. 33-76, mar. 2014.

ALBUQUERQUE, Roberto Chacon. A propriedade informática. Campinas: Russel, 2006.

ALVES, Gustavo Baptista; SILVA FILHO, Paulo Cesar da; MENDONÇA, Victor Furtado (Coords.). Tributação \& Telecomunicações. São Paulo: Quartier Latin, 2016.

AMANT, Kirk St. Understanding IT Outsourcing: a perspective for managers and decision makers. In: (Ed.). IT Outsourcing: concepts, methodologies, tools, and applications. Hershey: Business Science Reference, p. XXXII-LIX, 2010. Disponível em: <https://goo.gl/h6x8NE>. Acesso em: 3 set. 2016.

AMARO, Luciano. Direito tributário brasileiro. 15. ed. São Paulo: Saraiva, 2009. . Imposto de Renda: Regime Jurídico. In: MARTINS, Ives Gandra da Silva; NASCIMENTO, Carlos Valder do; MARTINS, Rogério Gandra da Silva. Tratado de direito tributário. São Paulo: Saraiva, 2011.

Questões Sobre a Periodicidade da Apuração do Imposto de Renda. In: ROCHA, Valdir de Oliveira. Imposto de Renda e ICMS: problemas jurídicos. São Paulo: Dialética, 1995.

ANDERLE, Ricardo. Conflitos de competência tributária entre o ISS, ICMS e IPI. 2015. Tese Doutorado em Direito - Pontifícia Universidade Católica de São Paulo, São Paulo, 2015.

ANDRADE, José Maria Arruda de. Conceitos de direito privado e normas de competência tributária. In: HORVATH, Estevão; CONTI, José Maurício. SCAFF, Fernando Facury. Direito financeiro, econômico e tributário: estudos em homenagem a Regis Fernandes de Oliveira. São Paulo: Quartier Latin, 2014.

Economização do direito concorrencial. São Paulo: Quartier Latin, 2014.

ANDREESSEN, Marc. Why Software is Eating the World. The Wall Street Journal, 20 Ago. 2011. Disponível em: <http://www.wsj.com/articles/SB10001424053111903480904576512250915629460>. Acesso em: $1^{\circ}$ ago. 2016. 
ANJO, Rubya Floriani dos. Regime tributário das telecomunicações. Tese (Doutorado em Direito) - Faculdade de Direito, PUC-SP, 2013.

ARAÚJO, Bráulio Santos Rabelo de. Convergência Tecnológica, Serviço Público e o Papel do Estado na Comunicação. In: COSTA, José Augusto Fontoura; ANDRADE, José Maria Arruda; MATSUO, Alexandra Mery Hansen (Org.). Direito: Teoria e experiência Estudos em homenagem a Eros Roberto Grau. Tomo I. São Paulo: Malheiros, 2013.

AREAS, Patricia de Oliveira. Propriedade Intelectual e Computação em Nuvens (Cloud Computing): aspectos do contrato de licença de uso do software como serviço (software as a service - SaaS). In: WACHOWICZ, Marcos (Coord.). Propriedade Intelectual \& Internet. vol. II. Curitiba: Juruá, 2011.

ARNOLD, Brian J. Fearful Symmetry: The Attribution of Profits 'in Each Contracting State'. Bulletin for International Taxation. vol. 61. n. 8. Amsterdam: IBFD. p. 321-327. 2007.

Time Threshold in Tax Treaties. Bulletin for International Taxation. Amsterdã: IBFD, p. 218-231. Jun./2008.

ARNOLD, Brian J.; SASSEVILLE, Jacques. Source Rules for Taxing Business Profits Under Tax Treaties. In: ; ZOLT, Eric M. The Taxation of Business

Profits Under Tax Treaties. Toronto: Canadian Tax Foundation, 2003.

ASCENÇÃO, José de Oliveira. Programa de Computador e Direito Autoral. In: GOMES, Orlando et al. A Proteção Jurídica do "Software". Rio de Janeiro: Forense, 1985.

Direito Autoral. Rio de Janeiro: Renovar, 1997.

ASSUNÇÃO, Matheus Carneiro. O ICMS na transferência eletrônica de software. Revista Jurídica da Presidência da República. vol. 11. n. 93. Brasília. p. 01-35. fev. - mai./2009.

ATALIBA, Geraldo. Hipótese de Incidência Tributária. 6. ed. São Paulo: Malheiros, 2002.

Periodicidade do Imposto de Renda. Revista de Direito Tributário. n. 63. São Paulo: Malheiros, 1994. 1968.

Sistema Constitucional Tributário Brasileiro. São Paulo: Revista dos Tribunais, ; BARRETO, Aires Fernandino. ISS e ICM: conflitos. Revista de Direito

Tributário. São Paulo: RT, v. 11-12, ano IV, p. 169-173, jan.-jun. 1980. 
ÁVILA, Humberto. Eficácia do Novo Código Civil na Legislação Tributária. In: GRUPENMACHER, Betina Treiger. Direito Tributário e o Novo Código Civil. São Paulo: Quartier Latin, 2004.

. Imposto sobre a Prestação de Serviços de Qualquer Natureza. Contrato de Leasing Financeiro. Decisão do Supremo Tribunal Federal. Local da Prestação e Base de Cálculo. Revista Dialética de Direito Tributário. n. 182. p. 133-144. nov. 2010.

Os conflitos de competência entre entes federados, homólogos ou diversos [ISS no estabelecimento prestador ou no local da prestação, ICMS nas ditas importações indiretas, ICMS e ISS nos serviços das empresas de comunicação, etc.). Soluções individuais e institucionais. Revista Internacional de Direito Tributário. v. 8. Belo Horizonte: Del Rey. p. 401-408. jul./dez. 2007.

. Sistema Constitucional Tributário. 4 ed. São Paulo: Saraiva, 2010.

. Teoria da Igualdade Tributária. São Paulo: Malheiros, 2009.

Teoria da Segurança Jurídica. 3. ed. São Paulo: Malheiros, 2014.

Teoria dos Princípios. 15 ed. São Paulo: Malheiros, 2014.

AVI-YONAH, Reuven S. A Tributação Internacional do Comércio Eletrônico. Revista Internacional de Direito Tributário. V. 06, p. 417- 473. jul./dez. 2006

. International Tax as International Law. University of Michigan Law. Public Law Research Paper n. 41. Michigan Law and Economics Research Paper n. 04-007. p. 1-16. mai./2004. Disponível em: <https://ssrn.com/abstract=516382>. Acesso em: 3 fev. 2017.

; CLAUSING, Kimberly A. Business Income (Article 7 OECD MC). Law \& Economics Working Papers Archive: 2003-2009. paper 74. University of Michigan Law School. Disponível em: <http://repository.law.umich.edu/law_econ_archive/art74/> . Acesso em: 1ํㅡ maio 2017.

AZAM, Rifat. E-Commerce Taxation and Cyberspace Law: The Integrative Adaptation Model. Virginia Journal of Law \& Technology. vol. 12. n. 5. p. 1-34. 2012 (g. n). Disponível em: <https://papers.ssrn.com/sol3/papers.cfm?abstract_id=1406416>. Acesso em: 2 abr. 2017.

AZEVEDO, Álvaro Villaça. Teoria Geral dos Contratos Típicos e Atípicos. 3. ed. São Paulo: Saraiva, 2009.

BAKER \& MCKENZIE. Integration of Bundled Cloud Offerings. In: Inform 2015/2016 Cloud Survey Trend Series. Disponível em:

<http://www.bakerinform.com/home/2016/2/3/integration-of-bundled-cloud-offerings >. Acesso em: 13 set. 2016.

BAKER, Philip. A tributação internacional no século XXI. Direito Tributário Atual. n. 19. São Paulo: Dialética, 2005. 
BAKER, Philip. Diverted Profits Tax: a partial response. British Tax Review. n 2. p. 167171. 2015.

BAKER, William B. Optimal International Taxation and Tax Competition: Overcoming the Contradictions. Northwestern Journal of International Law \& Business. vol. 22. p. 200-217. 2001-2002.

BAKKER, Anuschka. Seminar M - Taxation of software payments - an update. In: Is there a permanent establishment? Cahiers de Droit Fiscal International. vol. 94a. Rotterdam: Kluwer for the International Fiscal Association. 2009; cf. BIAC (Position Paper). 1977 OECD Model Tax Convention on Income and on Capital. Paris: BIAC, 1987.

BAL, Aleksandra. Tax Implications of Cloud Computing - How Real Taxes Fit into Virtual Clouds. Bulletin for International Taxation, vol. 66. n. 6. p. 335-339. jun./2012.

Taxation of Digital Supplies in the European Union and United States - What Can They Learn from Each Other? European Taxation. n. 6. IBFD. Jun./2015

The Sky's the Limit - Cloud-Based Services in an International Perspective. Bulletin for International Taxation. n. 9. p. 515-521. set./. 2014 - tradução livre.

BALEEIRO, Aliomar. Direito Tributário Brasileiro. 10. ed. Rio de Janeiro: Forense, 1991.

. Limitações Constitucionais ao Poder de Tributar. 7. ed. Atualizadora Misabel Abreu Machado Derzi. Rio de Janeiro: Forense, 2006.

BARBOSA, Denis Borges. Computer and Copyright: a Marriage of Inconvenience. The Copyright Magazine. Genebra: World Intellectual Property Organization, jun./1998.

Contratos de Propriedade Intelectual. Apostila V. In: Propriedade Intelectual. LLM em Direito Empresarial. IBMEC. s/a. Disponível em: <http://www.denisbarbosa.addr.com/paginas/apostilas/apostilas.html>. Acesso em: 23 mar. 2017. 1999.

. Licenças e cessão. Revista da ABPI, n. 40. São Paulo: ABPI, p. 29-30. mai./jun.

Tratado da Propriedade Intelectual. Tomo 1. São Paulo: Lumen Juris, 2010.

BARBOSA, Denis Borges; SIQUEIRA, Marcelo Gustavo Silva. Tributação da Propriedade Intelectual e do Comércio de Tecnologia. 2. ed. Rio de Janeiro: Lumen Juris, 2012.

BARBOSA, Luiz Roberto Peroba; CARPINETTI, Ana Carolina. "Aspectos Tributários dos Serviços Over the Top". Revista Dialética de Direito Tributário, n. 238. São Paulo: Dialética. p. 89-93. 2015.

BARRETO, Aires Fernandino. ISS na Constituição e na Lei. 2. ed. São Paulo: Dialética, 2005 . 
BARRETO, Aires Fernandino. ISS, PIS e COFINS não incidem sobre Locação de Bens Móveis. In: ROCHA, Valdir de Oliveira [Coord.]. Grandes Questões Atuais de Direito Tributário. v. 5. São Paulo: Dialética, 2001.

BARRETO, Paulo Ayres. Imposto sobre a renda e preços de transferência. São Paulo: Dialética, 2001.

BASSO, Guilherme Mastrichi. Terceirização e Mundo Globalizado - o encadeamento produtivo e a complementaridade de serviços como potencializadores da formalização de contratos. Revista do Tribunal Regional do Trabalho da 15² Região, n. 36, p. 79-107, 2010 .

BECKER, Alfredo Augusto. Teoria Geral do Direito Tributário. 4. ed. São Paulo: Noeses, 2007.

BELLAN, Daniel Vitor. Artistas e esportistas: o artigo 17 da Convenção Modelo da OCDE e dos tratados brasileiros. Revista de Direito Tributário Internacional. v. 4. n. 12. ago./2009.

BEVILAQUA, Clóvis. Código civil comentado. Rio de Janeiro: Francisco Alves. v. IV, art. 863, 1943.

BIANCHI, José Flávio. "Internet e Regulação: a ICANN à luz da teoria da regulação". Revista de Direito Setorial e Regulatório, Brasília, v. 2, n. 1. p. 247-268. maio 2016.

BIANCO, João Francisco. O Estabelecimento Permanente na Legislação do Imposto de Renda. In: ROCHA, Valdir de Oliveira. Grandes Questões Atuais do Direito Tributário. vol. 9. São Paulo: Dialética, 2005.

BIFANO, Elidie Palma. O Negócio Eletrônico e o Sistema Tributário Brasileiro. São Paulo: Quartier Latin, 2004.

BITTAR, Carlos Alberto. Os contratos de comercialização de "software". In:

(Coord.). Novos Contratos Empresariais. São Paulo: Revista dos Tribunais, 1990.

Os direitos da personalidade. Rio de Janeiro: Forense Universitária, 2000.

BLUM, Daniel W. Permanent Establishments and Action 1 on the Digital Economy of the OECD Base Erosion and Profit Shifting Initiative - The Nexus Criterion Redefined?

Bulletin for International Taxation, v. 69, n. 6/7. Amsterdam: IBFD. jun./jul. 2015.

BLUMENTHAL, Marjory; CLARK, David D. Rethinking the design of the Internet: the end-to-end arguments vs the brave new world. ACM Transactions on Internet

Technology, v. 1, n. 1, agosto 2001. p. 70-109. Disponível em:

<http://nms.lcs.mit.edu/6829-papers/bravenewworld.pdf>. Acesso em: 3 abr. 2016.

BOBBETT, Catherine; JONES, John Avery. The Treaty Definition of Royalties. Bulletin - Tax Treaty Monitor. jan./2006.

BONACCORSI, Cristiane Trevisani. Tributação de Softwares: SVA, ISS ou ICMS? In: RABELO FILHO, Antonio Reinaldo. 
BORGES, Fernanda da Fátima. As Características Gerais do Outsourcing - Uma Análise Comparada Brasil e França. La Grande Bibliothèque du Droit, Paris, 2014. Disponível em: <http://www.lagbd.org/index.php/As_Caracteristicas_Gerais_do_outsourcing__Uma_Analise_Comparada_Brasil_e_Fran\%C3\%A7a_(br)_(fr)>. Acesso em: 2 set. 2016.

Os aspectos jurídicos do outsourcing. Dissertação (Mestrado em Direito Comercial) - Faculdade de Direito, Universidade de São Paulo, São Paulo, 2014.

BORGES, José Souto Maior. Um ensaio interdisciplinar em direito tributário: superação da dogmática. Revista Dialética de Direito Tributário. n. 211. São Paulo: Dialética, 2011.

BOURCIER, Daniele; DE FILIPPI, Primavera. Cloud Computing: New Research Perspectives for Computers and Law. 13th International Conference of Artificial Intelligence \& Law, set. 2012 (g. n). Disponível em:

<http://papers.ssrn.com/sol3/papers.cfm?abstract_id=2097153>. Acesso em: 10 mar. 2017.

BOWER, Joseph L.; CHRISTENSEN, Clayton M. Disruptive Technologies: Catching the Wave. Harvard Business Review, Jan.-Fev. 1995.

BOYLE, Michael P. The Emerging International Tax Environment for Electronic Commerce. Tax Management International. n. 28. p. 357-382. Jun. 1999.

BOZZA, Fábio Piovesan. Planejamento Tributário e Autonomia Privada. Série Doutrina Tributária v. XV. São Paulo: Quartier Latin, 2015.

BRANCHER, Paulo Marcos Rodrigues. Contratos de Software. Florianópolis: Visual Books, 2003.

BRASIL. Conselho Administrativo de Recurso Fiscais. Processo no ${ }^{-}$16327.720552/201407. Segunda Turma. Conselheiro Relator João Victor Ribeiro Aldinucci. Brasília, DF, 16 mar. 2017. verde, 2000.

Ministério da Ciência e Tecnologia. Sociedade da Informação no Brasil: livro . Ministério das Comunicações. Apresentação da Proposta de Novo Modelo de Telecomunicações. Brasília, DF, 2015. Disponível em:

<http://www.mc.gov.br/publicacoes>. Acesso em: 3 abr.2016.

. Ministério da Fazenda. Secretaria da Receita Federal. O Brasil e o Comércio

Eletrônico. Brasília, abr. 2000. Disponível em:

<http://idg.receita.fazenda.gov.br/dados/receitadata/estudos-e-tributarios-e-

aduaneiros/estudos-e-estatisticas/estudos-diversos/brasil-e-o-comercio-eletronico>. Acesso em: 2 dez. 2016.

Superior Tribunal de Justiça. Agravo em Recurso Especialno ${ }^{0}$ 487.317/RS.

Primeira Turma. Relator Ministro José Delgado. Brasília, DF, 27.10.1997.

. Superior Tribunal de Justiça. AgRg no AREsp n⿳0 32.547/PR. Segunda Turma.

Relator Ministro Humberto Martins. Brasília, DF, 27.10.2011. 
BRASIL. Superior Tribunal de Justiça. Recurso Especial nº 123.022/RS. Primeira Turma. Relator Ministro Humberto Martins. Brasília, DF, 15.04.2014.

. Supremo Tribunal Federal. Agravo Regimental no Recurso Extraordinário no 258.870/SP. Segunda Turma. Relator Ministro Eros Grau. Brasília, DF, 31.7.2008.

. Supremo Tribunal Federal. Recurso Extraordinário no ${ }^{0}$ 176.626-3/SP. Primeira Turma. Relator Ministro Sepúlveda Pertence. Brasília, DF, 11.12.1998.

. Supremo Tribunal Federal. Recurso Extraordinário no ${ }^{0}$ 191.454-8/SP. Primeira Turma. Relator Ministro Sepúlveda Pertence. Brasília, DF, 6.8.1999.

Supremo Tribunal Federal. Recurso Extraordinário nº 199.464-9/SP. Primeira Turma. Relator Ministro Ilmar Galvão. Brasília, DF, 30.4.1999.

. Supremo Tribunal Federal. Recurso Extraordinário no Virtual. Relator Ministro Luiz Fux. Brasília, DF, 4.10.2012.

. Tribunal de Contas da União. TC 025.994/2014-0. Acórdão nº 1739/2015. Plenário. Relator: Benjamin Zymler. Brasília, DF, 15 jul. 2015. Disponível em: $<$ https://contas.tcu.gov.br/juris/Web/Juris/ConsultarTextual2/Jurisprudencia.faces?numero Acordao=1739>. Acesso em: 2 jun. 2016.

BRAUNER, Yariv. An International Tax Regime in Crystallization. Tax Law Review, n. 56, New York, p. 259-328, 2003. Disponível em:

$<$ http://scholarship.law.ufl.edu/cgi/viewcontent.cgi?article=1009\&context=facultypub $>$. Acesso em: 13 set. 2016).

Por que os Estados Unidos firmam Tratados Tributários? E por que não têm Tratado Tributário com o Brasil? Direito Tributário Atual. n. 26. São Paulo: Dialética. p. 109-128. 2011.

BRAUNER, Yariv; BAEZ, Andrés. Withholding Taxes in the Service of BEPS Action 1: Address the Tax Challenges of Digital Economy. IBFD White Papers. Amsterdam: IBFD. p. 1-33. 2015.

BUHLER, Ottmar. Principios de Derecho International Tributario. Madrid: Editorial de Derecho Financeiro, 1968.

CALDERARO, Francisco R. S. Regime legal dos royalties referentes a patentes de invenção, marcas de indústria e comércio, assistência técnica, científica, administrativa ou semelhantes. CHAVES, Antonio et al. Tecnologia, importação - exportação. São Paulo: CTE, 1976.

CALIENDO, Paulo. Da Tributação do Software nos Acordos Internacionais contra a Dupla Tributação da Renda. In: TÔRRES, Heleno Taveira (Coord.). Direito Tributário Internacional Aplicado. vol. II. São Paulo: Quartier Latin, 2004.

Estabelecimentos Permanentes em Direito Tributário Internacional. São Paulo: RT, 2005. 
CALIENDO, Paulo. Relações entre estabelecimento permanente e matriz: da recepção falha no Direito Brasileiro. In: SCHOUERI, Luís Eduardo; BIANCO, João Francisco (Coords.). Estudos de Direito Tributário em Homenagem ao Prof. Gerd Willi Rothmann. São Paulo: Quartier Latin. 2016.

CALIENDO, Paulo; TORRÊS, Heleno Taveira. Regime Tributário do Comércio Eletrônico no Brasil. Revista Interesse Público. Ano 7. n. 33. p. 169-194. set/out de 2005.

CANTO, Gilberto de Ulhôa; SOUZA, Antônio Carlos Garcia; MUNIZ, Ian de Porto Alegre. Imposto sobre a Renda e Proventos de Qualquer Natureza. In: MARTINS, Ives Gandra da Silva (Coord.). O Fato Gerador do Imposto sobre a Renda e Proventos de Qualquer Natureza. São Paulo: Resenha Tributária, 1986.

CARPENTER, Robert H. Walking From Cloud to Cloud: The Portability Issue in Cloud Computing. Washington Journal of Law, Technology \& Arts, vol. 6, n. 1, p.1-14, 2010. Disponível em: <http://lawlib.wlu.edu/CLJC/index.aspx?mainid=1375\&issuedate=201102-14\&homepage=no>. Acesso em: 2 jun. 2016.

CARPINETTI, Ana Carolina. Tributação pelo ICMS da Venda de Conteúdo pela Internet por meio de Download. Dissertação (Mestrado em Direito Tributário) Pontifícia Universidade Católica de São Paulo, São Paulo, 2012, p. 12.

CARR, Nicholas. The Big Switch: Rewiring the World, from Edison to Google. New York: W. W. Norton \& Company, 2008.

CARRAZZA, Roque Antonio. ICMS. 11. ed. São Paulo: Malheiros, $2006 .$.

Reflexões sobre a Obrigação Tributária. São Paulo: Noeses, 2010, p. 35-36.

CARVALHO, Marcelo Sávio Revoredo Menezes de. A Trajetória da internet no Brasil: do surgimento das redes de computadores à instituição dos mecanismos de governança. Dissertação (Mestrado em Ciências de Engenharia de Sistemas e Computação) Faculdade de Engenharia, Universidade Federal do Rio de Janeiro, 2006, p. 8. Disponível em: 〈http://www.cos.ufrj.br/uploadfile/1430748034.pdf〉. Acesso em: 3 maio 2016.

CARVALHO, Paulo de Barros. ISS - diversões públicas. Revista de Direito Tributário. n. 17/18. São Paulo: RT. jul.-dez./1981.

Não-incidência do ISS sobre Atividades de Franquia (Franchising). Revista de Estudos Tributários. n. 56. p. 65-79 [71]. jul. ago. de 2007.

O princípio da territorialidade no regime de tributação da renda mundial (universalidade). Revista de Direito Tributário. n. 76. São Paulo: Malheiros. p. 5-14 [9].

CASTRO, Leonardo Freitas de Moraes. Tributação da Transferência Internacional de Tecnologia: Importantes Diferenças entre sua Qualificação como Royalties ou Ganho de Capital. Revista Dialética de Direito Tributário. n. 213. São Paulo: Dialética. p. 80-101. jun./2013.

CASTRO, Marcus Faro de. Formas jurídicas e mudança social: interações entre o direito, a filosofia, a política e a economia. São Paulo: Editora Saraiva, 2012, Prefácio. 
CATÃO, Marcos André Vinhas; JANOLIO, Julio Salles Costa. Novas Tendências da Tributação sobre o Comércio Eletrônico. In: TÔRRES, Heleno Taveira (Coord.). Direito Tributário Internacional Aplicado, Vol. IV, São Paulo: Quartier Latin, 2007.

CERIONI, Luca. The New "Google Tax": The "Beginning of the End" for Tax Residence as a Connecting Factor for Tax Jurisdiction? European Taxation. n. 5. p. 185-195. mai./2015.

CERN. "The birth of the web". Disponível em: 〈http://home.cern/topics/birth-web〉. Acesso em: 3 maio.2016.

CERQUEIRA, Tarcísio Queiroz. Software: direito autoral e contratos. Rio de Janeiro: Forense, 1993.

Software: direito e tecnologia da informação: legislação, doutrina, práticas comerciais, modelos de contratos. Curitiba: Juruá, 2011.

CEZAROTI, Guilherme. ICMS no comércio eletrônico. São Paulo: MP Editora, 2005.

CHAVES, Antonio. Direito de autor. Rio de Janeiro: Forense, 1987.

CHOUERI, Luís Eduardo. Tributação e cooperação internacional. Revista Fórum de Direito Tributário. ano 2. n. 7. jan./fev. 2004, cópia da versão digital, s/n página).

COCKFIELD, Arthur J. The Law and Economics of Digital Taxation: Challenges to Traditional Tax Laws and Principles. Bulletin for International Fiscal Documentation, vol. 56, 2002.

. BEPS and Global Digital Taxation. Tax Notes International, vol. 75, n. 11, p. 933-940. set./2014.

COELHO, Sacha Calmon Navarro. Curso de direito tributário brasileiro. 6. ed. Rio de Janeiro: Forense, 2002.

COLLIN, Pierre; COLIN, Nicolas. Task Force on Taxation of the Digital Economy, jan. 2013. Disponível em:

<http://www.hldataprotection.com/files/2013/06/Taxation_Digital_Economy.pdf>. Acesso em: 9 set. 2016.

COLOMBO, Daniel Gama e. A política pública de incentivo ao setor de informática no Brasil a partir da década de 90: uma análise jurídica. $261 \mathrm{f}$. Dissertação de Mestrado, Faculdade de Direito, Universidade de São Paulo, 2009.

COMITÊ GESTOR DA INTERNET NO BRASIL (CGI.br). "Sobre o GGI”. Disponível em: <http://www.cgi.br/sobre/>. Acesso em: 11 abr. 2016.

CONSÓRCIO World Wide Web - W3C. "Sobre o W3C". Disponível em: <http://www.w3c.br/Noticias/InformacoesSobreOW3cESobreExtensoesDeMidiaCriptogra fadaeme>. Acesso em: 10 abr. 2016.

CORKERY, Jim; FORDER, Jay; SVANTESSON, Dan; MERCURI, Enrico. Taxes, the Internet and the Digital Economy. Revenue Law Journal. vol. 23. n. 1. Jan. 2013. 
COSTA, Alcides Jorge. Conceito de Renda Tributável. In: MARTINS, Ives Gandra da Silva (Coord.). Estudos sobre o Imposto de Renda (Em memória de Henry Tilbery). São Paulo: Resenha Tributária, 1994.

Direito tributário e direito privado. In: MACHADO, Brandão (Org.). Direito Tributário - estudos em homenagem a Ruy Barbosa Nogueira. São Paulo: Saraiva, 1984.

COSTA, Renato Lopes. Tecnologia: um recurso estratégico no processo de externalizar. Estudos do ISCA - Instituto Superior de Ciências do Trabalho e da Empresa, série IV, n. 06, p .1-8, 2013.

COWHEY, Peter; KLEEMAN, Michael. Unlocking the Benefits of Cloud Computing for Emerging Economies - A Policy Overview. UC San Diego, 2012. Disponível em: <irps.ucsd.edu/Cowhey>. Acesso em: 13 out. 2016.

CREMER, Jacques et al. Cloud ecosystem and platforms competition. DigiWorld Economic Journal, n. 85, jan.-abr. 2012, p. 14. Disponível em:

$<$ http://www.idate.org/en/Digiworld-store/Collection/Communications-Strategies_18/No85-Cloud-ecosystem-and-platforms-competition_670.html>. Acesso em: 2 jun. 2016.

CUNHA, Fábio da Lima. Os Serviços sem Transferência de Tecnologia no Contexto dos Tratados para evitar a Dupla Tributação da Renda. Revista Dialética de Direito Tributário. n. 190. São Paulo: Dialética. p. 19-28. jul./2011.

DE LUCCA, Newton. Aspectos Jurídicos da Contratação Informática e Telemática. São Paulo: Saraiva, 2003.

DE SANTI, Eurico Marcos Diniz; ZILVETI, Fernando Aurelio; MOSQUERA, Roberto Quiroga. Tributação Internacional e dos Mercados Financeiro e de Capitais. São Paulo: Quartier Latin, 2005.

DENGO, Atílio. Comércio Eletrônico e Neutralidade Tributária. Revista Dialética de Direito Tributário. n. 95. São Paulo: Dialética. p. 18-34. ago./2003.

DERZI, Misabel Abreu Machado. O planejamento tributário e o buraco do Real. Contraste entre a Completabilidade do Direito Civil e a Vedação da Completude no Direito Tributário. In: FERREIRA, Eduardo Paz; TÔRRES, Heleno Taveira; PALMA, Clotilde Celorico (Org.). Estudos em Homenagem ao Professor Doutor Alberto Xavier Economia, Finanças Públicas e Direito Fiscal. Vol. II. Coimbra: Almedina, 2013.

Periodicidade do Imposto de Renda. Revista de Direito Tributário. n. 63. São Paulo: Malheiros, 1994. 2008.

Direito Tributário, Direito Penal e tipo. 2. ed. São Paulo: Revista dos Tribunais,

DHAR, Subhankar. From Outsourcing to Cloud Computing: Evolution of IT Services. Management Research Review, vol. 35 n. 8, p. 664-675, 2012. 
DOERNBERG, Richard L., HINNEKENS, Luc, HELLERSTEIN, Walter; LI, Jinyan. Electronic Commerce and Multijurisdictional Taxation. The Hague: Kluwer Law International, 2001.

DORNELLES, Francisco Neves. A dupla tributação internacional da renda. Rio de Janeiro: Fundação Getúlio Vargas, 1979.

. O Modelo da ONU para Eliminar a Dupla Tributação da Renda, e os Países em Desenvolvimento. In: TAVOLARO, Agostinho Toffoli; MACHADO, Brandão; MARTINS, Ives Gandra da Silva. Princípios Tributários no Direito Brasileiro e Comparado. Estudos em Homenagem a Gilberto de Ulhôa Canto. Forense: Rio de Janeiro, 1988.

EMERENCIANO, Adelmo da Silva. Tributação no Comércio Eletrônico. São Paulo: IOB, 2003.

ENGLISCH, Joachim. BESP Action 1: Digital Economy - EU Law Implications. British Tax Review. vol. 60. p. 280-307. 2015.

EUROPEAN PARLIAMENT. Directive 2009/25/EC - Legal Protection of Computer Programs. 23 abr. 2009.

FALCÃO, Amílcar de Araújo. Introdução ao Direito Tributário. Rio de Janeiro: Forense, 1987.

FERRAZ JUNIOR, Tercio Sampaio. A terceirização e a Constituição. Folha de São Paulo, São Paulo, 15 maio 2015. Opinião. Disponível em: <http://folha.com/no1627694>. Acesso em: 5 set. 2016.

. Da limitação constitucional a estrangeiros em empresas jornalísticas em face das novas tecnologias. In: COSTA, José Augusto Fontoura; ANDRADE, José Maria Arruda; MATSUO, Alexandra Mery Hansen (Org.). Direito: Teoria e experiência - Estudos em homenagem a Eros Roberto Grau. Tomo I. São Paulo: Malheiros, 2013.

Simulação e negócio jurídico indireto. No Direito Tributário e à luz do novo Código Civil. Revista Fórum de Direito Tributário. Belo Horizonte: Fórum. ano 8. n. 48. p. 09-25. nov./dez. 2010.

FILIPPI, Primavera de. Taxing the cloud: introducing a new taxation system on data collection? Internet Policy Review, vol. 2, n. 2, mai. 2013. Disponível em:

$<$ http://policyreview.info/articles/analysis/taxing-cloud-introducing-new-taxation-systemdata-collection>. Acesso em: 11 abr. 2016.

FLYNN, Channing et al. Session 7. Navigating the Cloud: Keeping Pace with the Evolving Taxation of Cloud Computing and E-Commerce. Taxes - The Tax Magazine, p. 77-88, Jun. 2013.

FONSECA, Andreza Ribeiro. A Qualificação dos Rendimentos de Assistência Técnica e Serviços Técnicos no Âmbito dos Acordos contra a Dupla Tributação Assinados pelo Brasil. Direito Tributário Atual. n. 32. São Paulo: Dialética. 2014. 
FRANCO, Karin Klempp. A regulação da contratação internacional de transferência de tecnologia. Tese (Doutorado em Direito) - Universidade de São Paulo, São Paulo, 2010 .

FRONDA, Aaran. BEPS and the digital economy: Why is it so taxing to tax? International Tax Review v. 25, n. 13, jul/ago 2014.

FUNKE, Martha. Conceito de 'multicloud' começa a atrair usuários. Valor Econômico. Caderno Especial "Negócios Conectados”. São Paulo, 17-19 set./2016.

GALENDI JÚNIOR, Ricardo André; GALDINO, Guilherme Silva. Desafios da Economia Digital: Do Problema Hermenêutico ao Desequilíbrio na Alocação de Jurisdição. In: GOMES, Marcus Lívio; SCHOUERI, Luís Eduardo. A Tributação Internacional na Era Pós BEPS, vol. III. Rio de Janeiro: Lumen Juris, 2016.

GALHARDO, Luciana Rosanova. Serviços técnicos prestados por empresa francesa e imposto de renda na fonte. Revista Dialética de Direito Tributário. n. 31. São Paulo: Dialética, 1998.

GALLINDO, Sergio Paulo Gomes. Marco Civil da Internet e Serviços na Nuvem. Hermenêutica jurídica e tributação como indutores de inovação tecnológica. Dissertação (Mestrado em Direito Político e Econômico) - Universidade Presbiteriana Mackenzie, São Paulo, 2017.

GAOUA, Noah. Taxation of the Digital Economy: French Reflections. European Taxation, Volume 54, n. 1, Amsterdam: IBFD. p. 10-14. jan./2014.

GARCIA, Ana María Delgado; CUELLO, Rafael Oliver. Direct Taxation of Electronic Commerce in Spain. European Taxation. Jan./2013; BOBBETT, Catherine; JONES, John Avery. The Treaty Definition of Royalties. Bulletin - Tax Treaty Monitor. jan./2006

GAUDIN, Sharon. Global public cloud market expected to hit \$204B in 2016.

ComputerWorld, jan./2016. Disponível em: <http://www.computerworld.com/article/3026396/cloud-computing/global-public-cloudmarket-expected-to-hit-204b-in-2016.html>. Acesso em: 4 ago. 2016.

GENY, François. O particularismo no Direito Fiscal. Revista de Direito Administrativo. v. 20. Rio de Janeiro: Fundação Getúlio Vargas, 1950.

GETSCHKO, Demi. As origens do Marco Civil da Internet. In: LEITE, George Salomão; LEMOS, Ronaldo (Coord.). Marco Civil da Internet. São Paulo: Atlas, 2014.

GODOI, Marciano Seabra de. Crítica à Jurisprudência Atual do STF em Matéria Tributária. São Paulo: Dialética, 2011.

GOMES, Orlando. A proteção dos programas de computador. In: . et al. A Proteção Jurídica do "Software". Rio de Janeiro: Forense, 1985.

Contratos. Rio de Janeiro: Forense, 2008.

GONÇALVES, Carlos Roberto. Direito civil brasileiro. Vol. 2. 6. ed. São Paulo: Saraiva, 2009. 
GONÇALVES, José Artur Lima. Imposto sobre a Renda - Pressupostos

Constitucionais. São Paulo: Malheiros, 2002.

GONÇALVES, Renato Lacerda de Lima. A tributação da propriedade intelectual no Brasil. Tese (Doutorado em Direito) - Pontifícia Universidade Católica de São Paulo, São Paulo, 2010.

A Tributação do Software no Brasil. São Paulo: Quartier Latin, 2005.

GOULDING, Charles R.; BONAFE, Andressa; GOLDMAN, Jacob. The R\&D Tax Credit Aspects of the Health Cloud. Corporate Business Taxation Monthly, p. 11-14, mar. 2014.

; GOLDMAN, Jacob; e GENDLER, Cassandra. The Tax Aspects of Cloud Computing and Data Centers. Corporate Business Taxation Monthly, p. 9-12, dez. 2010.

GRAU, Eros Roberto. Por que tenho medo dos juízes (a interpretação/aplicação do direito e os princípios). 6. ed. São Paulo: Malheiros, 2014.

GRECO, Marco Aurélio. Aspectos Tributários do Comércio Eletrônico. In: UCKMAR, Victor; ALTAMIRANO, Alejandro C.; TÔRRES, Heleno Taveira. Impuestos sobre el comercio internacional. Buenos Aires: Editorial Ábaco de Rodolfo Depalma, 2003.

Comércio Exterior e Novas Realidades - Problemas Emergentes. In:

Internet e Direito. São Paulo: Dialética, 2000.

Sobre o Futuro da Tributação: a Figura dos Intangíveis. Revista Direito

Tributário Atual, n. 25, São Paulo: Dialética, v. 25, 2011, p. 108-120.

Tributação do Comércio Eletrônico. In: Internet e Direito. São Paulo: Dialética, 2000.

GRECO, Marco Aurélio et al. Manual de Direito Tributário Internacional. São Paulo: Dialética, 2012.

GREGORIO, Ricardo Marozzi. Um Regime para a Tributação Internacional: Perspectivas para o Brasil. Direito Tributário Atual. n. 24. São Paulo: Dialética. p. 464-487. 2010.

GRUND, Fabíola Fernandes; RIVERO, Juliana Burkhart. Tributação de Valores Remetidos ao Exterior pela Aquisição de Software e por Serviços de Administração e Suporte a estes Relacionados. Revista Dialética de Direito Tributário. n. 119. São Paulo: Dialética. p. 19-32. ago./2005.

GUTIÉRREZ, Carlos. The UN Model and the BRICS Countries - Another View. Chapter 12. In: ; PERDELWITZ, Andreas. Taxation of Business Profits in the 21st Century. Amsterdam: IBFD, 2013.

GUTIÉRREZ, Horacio E. Peering Through the Cloud: The Future of Intellectual Property and Computing. The Federal Circuit Bar Journal, George Washington University Law School, vol. 20, n. 04, jun. 2011. 
HADFIELD, Gillian. Legal Infrastructure and the New Economy. USC Law Legal Studies Paper. n. 10-8 Disponível em: <https://ssrn.com/abstract=1567712>. Acesso em: 10 dez. 2016.

HEINSEN, Oliver; VOSS, Oliver. Cloud Computing under Double Tax Treaties: A German Perspective. Intertax, v. 40, n. 11. Alphen aan Den Rijn: Kluwer Law International, 2012.

HELLERSTEIN, Walter. Jurisdiction to Tax in the Digital Economy: Permanent and Other Establishments. Bulletin for International Taxation, v. 68, n. 6/7. Amsterdam: IBFD. jun./jul. 2014.

Jurisdiction to Tax Income and Consumption in the New Economy: a Theoretical and Comparative Perspective. Georgia Law Review. vol. 38. n. 01. p. 1-70. 2003.

HEREDIA, Alejandro García. Copyright and Software and Spanish Tax Treaties: An Issue of Balance between Technology-Importing and Technology-Exporting Countries.

European Taxation. vol. 46. n. 1. jan./2006.

HIGUCHI, Hiromi. Imposto de Renda das Empresas - Interpretação e prática. São Paulo: IR Publicações, 2017.

HILÚ NETO, Miguel. Imposto sobre Importações e Bens Virtuais. In: SCHOUERI, Luís Eduardo. Imposto de Renda e o Comércio Eletrônico. In: et al (Org.).

HOMSY, Leonardo; BRASIL, Isaque. ICMS e ISS na Economia Digital. In: RABELO FILHO, Antonio Reinaldo; ALVES, Gustavo Baptista; SILVA FILHO, Paulo Cesar da; MENDONÇA, Victor Furtado (Coords.). Tributação \& Telecomunicações. São Paulo: Quartier Latin, 2016.

HON, W. Kuan; MILLARD, Christopher; WALDEN, Ian. Negotiating Cloud Contracts: Looking at Clouds from Both Sides Now. Stanford Technology Law Review, vol. 16, n. 1, p. 79-129, 2012. Disponível em: <http://stlr.stanford.edu/pdf/cloudcontracts.pd>. Acesso em: 9 set. 2016.

HONGLER, Peter; PISTONE, Pasquale. Blueprints for a New PE Nexus to Tax Business Income in the Era of the Digital Economy. IBFD White Papers. Amsterdam: IBFD. 2015.

IAB - Internet Architecture Board. Disponível em: <https://www.iab.org/about/>. Acesso em: 3 abr. 2016.

IAZOLO, Daniel. The New Economy and the International Regulatory Framework. Kiel Working Paper n. 1030. Kiel Institute of World Economics. Kiel, mar. 2001.

IEEE - Advancing Technology for Humanity. Disponível em:

$<$ https://www.ieee.org/about/vision_mission.html>. Acesso em: $1^{\circ}$ mar. 2016.

IETF - Internet Engineering Task Force. Disponível em: 〈https://www.ietf.org/about/>. Acesso em: 3 abr. 2016. 
INSTITUTO BRASILEIRO DE GEOGRAFIA E ESTATÍSTICA (IBGE). Acesso à internet e à televisão e posse de telefone móvel celular para uso pessoal: 2014 . Rio de Janeiro: IBGE, 2016. 89p. Disponível em:

<http://www.ibge.gov.br/home/estatistica/populacao/acessoainternet2014/default.shtm>. Acesso em: 3 abr. 2016.

. O Setor de tecnologia da informação e comunicação no Brasil: 2003-2006.

Série: Estudos e pesquisas. Informação econômica. Rio de Janeiro: IBGE, 2009.

Disponível em: <http://biblioteca.ibge.gov.br/biblioteca-

catalogo?view=detalhes\&id=241716>. Acesso em: 23 maio 2016.

INTERACTIVE SERVICES ASSOCIATION - ISA. Logging On to Cyberspace Tax Policy - An Interactive Services Association Task Force White Paper. 1997.

Disponível em:

<http://www.wvu.edu/ lawfac/cchin/Logging_On_To_CyberSpace_Tax_Policy.html >. Acesso em: 24 maio 2016.

INTERNET SOCIETY. Mission. Disponível em: <http://www.internetsociety.org/whowe-are/mission>. Acesso em: 3 abr. 2016.

ITU - About International Telecommunication Union (ITU). Disponível em: <http://www.itu.int/en/about/Pages/default.aspx>. Acesso em: $1^{0}$ mar. 2016.

JARACH, Dino. El hecho imponible. 3. ed. Buenos Aires: Abeledo-Perrot, [s/d], p. 208/209.

JARNEVIC, Jean-Pierre. Droit Fiscal International. Paris: Economica, 1985.

JONES JR. John B.; MATTSON. Robert N.. General Report. In: Tax Treament of Computer Software. Cahiers de Droit Fiscal International. vol 73b. Rotterdam: Kluwer for the International Fiscal Association. p. 19-44. 1988.

KEMMEREN, Eric. Legal and Economic Principles Support an Origin and Import Neutrality-Based over a Residence and Export Neutrality-Based Tax Treaty Policy. In: LANG, Michael et al. (Coord.). Tax Treaties: Building Bridges between Law and Economics. Online Books IBFD, 2010, seção 5.

Source of income in globalizing economies: overview of the issues and a plea for an origin-based approach. Bulletin for International Taxation. Amsterdã: IBFD, p. 430452. 2006.

Source of income in globalizing economies: overview of the issues and a plea for an origin-based approach. Bulletin for International Taxation. n. 11. Amsterdã: IBFD, p. 37-47. nov./2006.

KPMG. Tax in the Cloud: a briefing for Tax Directors. United Kingdom, jan. 2012. Disponível em:

<https://www.kpmg.com/Global/en/IssuesAndInsights/ArticlesPublications/tax-in-thecloud/Documents/tax-in-the-cloud.pdf>. Acesso em: 7 set. 2016. 
KRAKOWIAK, Léo; KRAKOWIAK, Ricardo. Tributação aduaneira e problemas jurídicos decorrentes da informatização do comércio exterior. In: GRECO, Marco Aurélio (Coord.). Direito e Internet: relações jurídicas na sociedade informatizada. São Paulo: RT, 2001.

KRISHNAMURTHY, Vivek. Cloudy with a Conflict of Laws. Berkman Center for Internet \& Society - Harvard University Research Publication n. 2016-3, fev. 2016. Disponível em: <http://papers.ssrn.com/sol3/papers.cfm?abstract_id=2733350>. Acesso em: 2 abr. 2016.

LAINOFF, Steven R.; VAISH, Ramesh C.. General Report. In: Taxation of Income Derived of the Supply of Technology. Cahiers de Droit Fiscal International. vol. 82a. Rotterdam: Kluwer for the International Fiscal Association. 1997.

LAMETTI, David. The Cloud: Boundless Digital Potential or Enclosure 3.0? Virginia Journal of Law \& Technology, vol. 17, n. 3, 2012. Disponível em:

<http://papers.ssrn.com/sol3/papers.cfm?abstract_id=2077742>. Acesso em: 2 set. 2016.

LANG, Michael. Introduction to the Law of Double Taxation Conventions. 2 ed. Amsterdam: Linde, 2013.

LARENZ, Karl. Metodologia da Ciência do Direito. 5 ed. Lisboa: Fundação Calouste Gulbenkian, 2009.

LEE, Chang Hee. Impact of E-commerce on Allocation of Tax Revenue between Developed and Developing Countries. Journal of Korean Law. vol. 4. n. 1. p. 19-50. 2004.

LEHNER, Moris. Consideração Econômica e Tributária Conforme a Capacidade Contributiva. Sobre a Possibilidade de uma Interpretação Teleológica de Normas com Finalidades Arrecadatórias. In: SCHOUERI, Luís Eduardo; ZILVETI, Fernando Aurélio (Coord.). Direito Tributário. Estudos em Homenagem a Brandão Machado. São Paulo: Dialética, 1998.

LEINER, Barry M.; CERF, Vinton G. et al. Brief History of the Internet. XXX Disponível em: <http://www.internetsociety.org/internet/what-internet/historyinternet/brief-history-internet>. Acesso em: 3 mai. 2016.

LEONARDI, Marcel. Tutela e Privacidade na Internet. São Paulo: Saraiva, 2011.

LEONARDOS, Gabriel Francisco. Direito Tributário Internacional e Tributação da Transferência de Tecnologia no Brasil. Dissertação (Mestrado em Direito) Universidade de São Paulo, São Paulo, 1996.

. O Imposto de Renda de Fonte sobre os Pagamentos ao Exterior por Serviços Técnicos - Análise de um Caso de Renúncia Fiscal do Brasil. Revista Dialética de Direito Tributário, n. 40. São Paulo: Dialética. p. 32-48 [33/34]. jan./1999.

LI, Jinyan. Protecting the Tax Base in the Digital Economy. Paper on Selected Topics in Protecting the Tax Base of Developing Countries. Paper n. 9. United Nations. p. 1-49. Jun./2014. 
LINDSAY, David. What do the .XXX disputes tell us about Internet Governance? ICANN's Legitimacy Deficit in Context. Telecommunications Journal of Australia, Volume 63, Number 3. Monash University Faculty of Law Legal Studies Research Paper No. 2013/31, 2013. Disponível em: <http://telsoc.org/tja/2013-06-v63-n3/a432〉. Acesso em: 9 abr. 2016.

LIU, Fang et al. NIST Cloud Computing Reference Architecture. NIST Special Publication 500-292, 2011. Disponível em:

<http://ws680.nist.gov/publication/get_pdf.cfm?pub_id=909505>. Acesso em: 12 set. 2016.

LOBEL, Orly. The Law of the Platform. San Diego Legal Studies, Research Paper n. 16212, mar. 2016.

LOBO, Carlos Augusto da Silveira. National Report - Brazil. In: Tax Treament of Computer Software. Cahiers de Droit Fiscal International. vol. 73b. Rotterdam: Kluwer for the International Fiscal Association. p. 241-251. 1988).

LUCCA, Newton. Tributação e Internet. In: MARTINS, Ives Gandra da Silva (Coord.). Tributação na Internet. São Paulo: Revista dos Tribunais, 2001.

LYMER, Andrew; HASSELDINE, John [Eds.]. The International Taxation System. New York: Springer, 2002.

MACEDO, José Alberto Oliveira. Conflitos de Competência na Tributação do Consumo. Tese (Doutorado em Direito) - Faculdade de Direito, Universidade de São Paulo, São Paulo, 2013.

MACHADO, Hugo de Brito. Código Tributário Nacional Comentado. São Paulo: Revista dos Tribunais, 1999.

MACHADO, Raquel Cavalcanti Ramos. Competência Tributária: entre a rigidez do sistema e a atualização interpretativa. Tese (Doutorado em Direito) - Faculdade de Direito, Universidade de São Paulo, São Paulo, 2013.

MALLINAK, Brenda. The revenue rule: a common law doctrine for the twenty-first century. Duke Journal of Comparative \& International Law. n. 16. p. 79-124. 2006. Disponível em: <http://scholarship.law.duke.edu/djcil/vol16/iss1/3>. Acesso em: 21 mar. 2017.

MANSO, Eduardo Vieira. Contratos de Direito Autoral. São Paulo: RT, 1989.

MANYKA, James et al. Disruptive technologies: Advances that will transform life, business, and the global economy. McKinsey Global Institute, mai. 2013. Disponível em: $<$ http://www.mckinsey.com/business-functions/business-technology/ourinsights/disruptive-technologies>. Acesso em: 2 jun. 2016.

MARANHÃO, Juliano. Ambiente virtual transforma profundamente categorias jurídicas. Revista Consultor Jurídico, São Paulo, 5 de dezembro de 2016. Disponível em: $<$ http://www.conjur.com.br/2016-dez-05/juliano-maranhao-ambiente-virtual-transformaprofundamente-direito>. Acesso em: 5 dez. 2016. 
MARINO, Francisco Paulo de Crescenzo. Contratos Coligados no Direito Brasileiro. São Paulo: Saraiva, 2009.

MARQUES NETO, Floriano Azevedo. Direito das Telecomunicações e ANATEL. In: SUNDFELD, Carlos Ari. Direito Administrativo Econômico. São Paulo: Malheiros, 2002.

MARTHA, Rutsel Silvestre J. Extraterritorial taxation in international law. In: MEESEN, Karl Matthias. Extraterritorial jurisdiction in theory and practice. Londres: Kluwer Law International, 1996.

MARTINS, Ives Gandra da Silva. Direito e Internet: relações jurídicas na sociedade informatizada. São Paulo: Revista dos Tribunais. p. 163-186. 2001.

MARTINS, Ricardo Lacaz; RABELLO, Carolina Malzoni Motta. Algumas considerações a respeito dos Contratos de Nível de Serviços - SLAs. In: SCHOUREI, Luís Eduardo. Internet: o direito na era virtual. Rio de Janeiro: Forense, 2001.

MARTINS, Sergio Pinto. Manual do Imposto sobre Serviços. $8^{\mathrm{a}}$ ed., São Paulo: Atlas, 2010.

MARTINS, Vergilio Antonio. Conceitos de outsourcing aplicados à operação de escritórios de gerenciamento de projetos. Dissertação (Mestrado em Engenharia) Faculdade Politécnica, Universidade de São Paulo, São Paulo, 2007.

MAZUR, Orly. Taxing the Cloud. California Law Review, California, vol. 103, n. 1, fev. 2015. Disponível em: <http://papers.ssrn.com/sol3/papers.cfm?abstract_id=2419644>. Acesso em: $1^{\underline{o}}$ abr. 2016.

MCLURE JR., Charles. Alternatives to the Concept of Permanent Establishment. CESifo Forum, v. 1, n. 3, p. 10-16. 2000 (g. n). Disponível em: <https://www.cesifogroup.de/portal/pls/portal/docs/1/1208178.PDF>. Acesso em: 21 mar. 2017.

MCLURE JR., Charles E. Thinking Straight About the Taxation of Electronic Commerce: Tax Principles, Compliance Problems, and Nexus. In: POTERBA, James M. Tax Policy and Economic. vol. 16. National Bureau of Economic Research. Jan. 2002, p. 115-140. Disponível em: <http://www.nber.org/chapters/c10864.pdf>. Acesso em: 13 mar. 2017.

; CORABI, Giampaolo. La Tributación sobre el Comercio Electrónico: Objetivos Económicos, Restricciones Tecnológicas y Legislación Tributaria. Buenos Aires: Depalma, 2000.

MCKINSEY GLOBAL INSTITUTE. The Internet of Things: mapping the value beyond the hype. June 2015. Disponível em: <http://www.mckinsey.com/businessfunctions/business-technology/our-insights/the-internet-of-things-the-value-of-digitizingthe-physical-world>. Acesso em: 3 abr. 2016.

MEIRELLES, Fernando S.. Pesquisa Anual do Uso de TI nas Empresas. São Paulo: FGV-EAESP, 27. ed., 2016. Disponível em: <http://eaesp.fgvsp.br/ensinoeconhecimento/centros/cia/pesquisa>. Acesso em: 5 abr. 2016. 
MELL, Peter; GRANCE, Timothy. The NIST definition of cloud computing. NIST Special Publication 800-145, 2011, p. 2. Disponível em:

<http://csrc.nist.gov/publications/nistpubs/800-145/SP800-145.pdf>. Acesso em: 5 set. 2016.

MELLO, Marco Aurélio. Interpretação Constitucional e Controvérsias Tributárias. Revista da Faculdade de Direito da Universidade São Judas Tadeu. n. 01, p. 12-30, 2014. Disponível em: <http://www.usjt.br/revistadireito/>. Acesso em: 23 set. 2016.

MELO, José Eduardo Soares de. Contratos e Tributação - Noções Fundamentais. São Paulo: Malheiros, 2015.

MEMO 13/1042, da Comissão Europeia: Disponível em: <http://europa.eu/rapid/pressrelease_MEMO-13-1042_en.htm>. Acesso em: 6 abr. 2016.

METTLER, Ann; WILLIAMS, Anthony D. The Rise of the Micro-Multinational: How Freelancers and Technology-Savvy Start-Ups Are Driving Growth, Jobs and Innovation. The Lisbon Council Policy Brief, 2011.

MIRANDA, Pontes de. Tratado de Direito Privado - Parte Geral. Negócios Jurídicos: Representação. Conteúdo. Forma. Prova. Tomo III. São Paulo: RT, 2012.

Tratado de direito privado. 3. ed. v. 11. Rio de Janeiro: Borsoi, 1971.

Tratado de Direito Privado. Tomo XXII - Parte Especial. Direito das

obrigações: Obrigações e suas espécies. Fontes e espécies de obrigações. São Paulo: RT, 2012.

MOLENAAR, Dick. Entertainers and Sportspersons Following the Updated OECD Model (2014). Bulletin for International Taxation, v. 69, n. 1. Amsterdã: IBFD, p. 430-452. 2006.

MORAES, Bernardo Ribeiro. Doutrina e Prática do Imposto sobre Serviços. $1^{\mathrm{a}}$ ed. São Paulo: Revista dos Tribunais, 1978.

MOREIRA FILHO, Aristóteles. A Aplicação do Princípio da Territorialidade Fiscal e o Conceito de Fonte na Tributação da Renda Auferida pelo Não-Residente, no Brasil, a Partir de Operações de Transferência de Tecnologia. In: TÔRRES, Heleno Taveira. Direito Tributário Internacional Aplicado. vol. V. São Paulo: Quartier Latin, 2008.

MOREIRA JUNIOR, Gilberto de Castro; ALMEIDA, Flora Ferreira. Cloud Computing e a Tributação do Software as a Service (SaaS). In: SCHOUERI, Luís Eduardo; BIANCO, João Francisco (Coords.). Estudos de Direito Tributário em Homenagem ao Prof. Gerd Willi Rothmann. São Paulo: Quartier Latin. 2016.

MORENO, André Báez. The Taxation of Technical Services under the United Nations Model Double Taxation Convention: A Rushed - Yet Appropriate - Proposal for (Developing) Countries? World Tax Journal. Vol. 7, n. 3. Set./2015.

MOSQUERA, Roberto Quiroga. Renda e proventos de qualquer natureza: o imposto e o conceito constitucional. São Paulo: Dialética, 1996. 
MOSQUERA, Roberto Quiroga. Tributação no Mercado Financeiro e de Capitais. São Paulo: Dialética, 1998.

MOSQUERA, Roberto Quiroga; LOPES, Alexsandro Broedel Lopes (Coord.). Controvérsias jurídico-contábeis (aproximações e distanciamentos). São Paulo: Dialética, 2010.

MOTTA FILHO, Marcello Martins. Ensaio jurídico sobre a computação em nuvem (cloud computing). Revista Tributária e de Finanças Públicas, v. 22, n. 116, p. 175-201, maio/jun. 2014.

MUSGRAVE, Peggy. B. Principles for Dividing the State Corporate Tax Base. In: McLURE JR., Charles E. (Ed.). The State Corporation Income Tax: Issues in Worldwide Unitary Combination. Stanford: Hoover Institution Press, 1984.

NABAIS, José Casalta. A Soberania Fiscal no Actual Quadro de Internacionalização, Integração e Globalização Econômicas. In: Por um Estado Fiscal Suportável. Estudos de Direito Fiscal. Lisboa: Almedina, 2005.

NEWTON, Jack. Is Cloud Computing Green Computing? General Practice, Solo \& Small Firm Division - GPSOLO Magazine, American Bar Association, Chicago, vol. 27, n. 8, dez. 2010. Disponível em: <http://www.americanbar.org/content/newsletter/publications/gp_solo_magazine_home/gp _solo_magazine_index/solo_lawyer_cloud_energy_pollution_environment.html >. Acesso em: 2 jun. 2016.

NÓBREGA FILHO, Raimundo G. (Ed.). “A evolução do microcomputador”. Cadernos de textos da disciplina Introdução ao Computador. Departamento de Informática.

Universidade Federal da Paraíba. Disponível em:

<http://www.di.ufpb.br/raimundo/HistoriaDoPC/PChist1.htm>. Acesso em: 14 abr. 2016.

NOVO, Diogo da Silva. Algumas Notas sobre a Determinação da Residência no CIRS: a Figura da Residência Fiscal Parcial. Direito Tributário Atual, n. 36. São Paulo: IBDT, 2016.

NOVOA, César García. Reflexiones sobre la Influencia de la Globalización en los Principios Tributarios. In: TÔRRES, Heleno Taveira (Coord.). Direito Tributário Internacional Aplicado. São Paulo: Quartier Latin, 2003.

NÚCLEO DE INFORMAÇÃO E COORDENAÇÃO DO PONTO BR (NIC.br). "Sobre o NIC.br". Disponível em: <http://nic.br/sobre/>. Acesso em: 11 abr. 2016.

NUNES, Renato. A Territorialidade Material no Ordenamento Jurídico Brasileiro e seus Efeitos quanto à Tributação de Renda Auferida por Pessoa Não-Residente. In: TÔRRES, Heleno Taveira (Coord.). Direito Tributário Aplicado, v. IV. São Paulo: Quartier Latin, 2007.

OECD - Organization for Economic Co-Operation and Development. Action Plan on Base Erosion and Profit Shifting. Paris: OECD Publishing, 2013. 
OECD - Organization for Economic Co-Operation and Development. Addressing the Tax Challenges of the Digital Economy, Action 1 - 2015 Final Report. Paris: OECD Publishing, 2015.

Are the Current Treaty Rules for Taxing Business Profits Appropriate for ECommerce? Final Report. Paris: OECD Publishing, 2004.

BEPS Action 1: Address the Tax Challenges of the Digital Economy, Public Discussion Draft. Paris: OECD Publishing, 2014.

Cloud Computing: The Concept, Impacts and the Role of Government Policy. OECD Digital Economy Papers n. 240, Paris: OECD Publishing, ago. 2014. Disponível em: <http://www.oecd-ilibrary.org/science-and-technology/cloud-computingthe-concept-impacts-and-the-role-of-government-policy_5jxzf4lcc7f5-en>. Acesso em: 7 jun. 2016.

Compilation of Comments Received in Response for Request of Inputs on Tax Challenges of Digital Economy. Paris: OECD Publishing, jan./2014, p. 66. Disponível em: <http://www.un.org/esa/ffd/tax/Beps/CommentsBrazil_BEPS.pdf>. Acesso em: 2 dez. 2016.

. Electronic Commerce. Policy Brief, n. 1, Paris, 1997. Disponível em:

<http://www.oecd.org/publications/Pol_brief/9701_pol.htm>. Acesso: 23 maio 2016.

Exploring Data-Driven Innovation as a New Source of Growth: Mapping the Policy Issues Raised by "Big Data". OECD Digital Economy Papers, n. 222, Paris: OECD Publishing, 2003.

. Issues Related to Article 17 of the OECDE Model Tax Convention.

Measuring the Digital Economy: A New Perspective. Paris: OECD Publishing, 2014, p. 140. Disponível em: <http://dx.doi.org/10.1787/9789264221796-en>. Acesso em: 3 maio 2016.

. Model Tax Convention on Income and Capital 2014. Full Version. Paris:

OECD Publishing, 2015.

OECD Digital Economy Outlook. Paris: OECD Publishing, 2015.

2011.

OECD Guide to Measuring the Information Society, Paris: OECD Publishing,

OECD Ministerial Meeting on the Digital Economy: Innovation, Growth and Social Prosperity, 21-23 Jun. 2016.

Tax Treaty Characterization Issues Arising from E-Commerce. Paris: OECD Publishing, 2001.

. The tax treatment of software (1992). In: OECD. Model Tax Convention on

Income and on Capital. Full Version. Paris: OECD Publishing, 2015. 
OLIVEIRA, Ricardo Mariz de. Fundamentos do Imposto de Renda. São Paulo: Quartier Latin, 2008.

; MATOS, Gustavo Martini de; BOZZA, Fábio Piovesan. Interpretação e Integração da Lei Tributária. In: MACHADO, Hugo de Brito (Coord.). Interpretação e Aplicação da Lei Tributária. São Paulo: Dialética, 2010.

ORRICO JUNIOR, Hugo. Pirataria de Software. São Paulo: MM Livros, 2004.

OWENS, Jeffrey. Tax Transparency: The "Full Monty". Bulletin for International Taxation, vol. 68, n. 9, p. 512-514, ago. 2014.

PAULA, Ivo de. Contratos Internacionais de E-business. São Paulo: Walmar, 2013.

PEDREIRA, José Luiz Bulhões. Imposto de Renda. 2. ed. Rio de Janeiro: Justec, 1971.

PELLEFIGUE, Julien. Transfer Princing Economics for the Digital Economy. Bulletin for International Taxation, v. 22, n. 2. Amsterdam: IBFD. p. 95-100. mar./abr. 2015.

PENTEADO, Luciano de Camargo. Direito das Coisas. São Paulo: RT, 2008.

PEREIRA, Alexandre Libório Dias. Programas de Computador, Sistemas Informáticos e Comunicações Eletrónicas: Alguns Aspectos Jurídico-Contratuais. Revista da Ordem dos Advogados, Ano 59, III, Lisboa, pp. 915-1000, dez. 1999. Disponível em: <http://hdl.handle.net/10316/12824>. Acesso em: 4 set. 2016.

. Protecção Jurídica e Exploração Negocial de Programas de Computador. Volume Comemorativo do 75 Tomo do Boletim da Faculdade de Direito. Universidade de Coimbra. p. 453-505. 2003.

PEREIRA, Caio Mário da Silva. Instituições de Direito Civil. v. 2. Rio de Janeiro: Forense, 2009.

PERONA, Costanzo. Tax Challenges of Digital Economy: cloud computing taxation issues and impacts. In: SCHOUERI, Luís Eduardo; BIANCO, João Francisco (Coords.). Estudos de Direito Tributário em Homenagem ao Prof. Gerd Willi Rothmann. São Paulo: Quartier Latin. 2016.

PESSERL, Alexandre Ricardo. Notas introdutórias a um estudo do direito de reprodução de obras autorais em ambiente digital. In: WACHOWICZ, Marcos (Coord.). Direto Autoral \& Marco Civil da Internet. Curitiba: Gedai Publicações, 2015.

PETRY, Rodrigo Caramori. Direito Constitucional Tributário Comparado: a Tributação nas Constituições do Brasil e de Outros Países. Direito Tributário Atual. n. 30. São Paulo: Dialética, p. 351-385. 2014.

PINTO, Dale. E-Commmerce and Source-Based Income Taxation. Amsterdam: IBFD, 2003.

PINTO, Dale. The need to reconceptualize the permanent establishment threshold.

Bulletin for International Taxation. n. 7. p. 266-279. jul./2006. 
PIRES, Manuel. Da dupla tributação jurídica internacional sobre o rendimento. Lisboa: Centro de Estudos Fiscais, 1984.

PIRES, Rita Calçada. Tributação Internacional do Rendimento Empresarial gerado através do Comércio Electrónico: desvendar mitos e construir realidades. Coimbra: Almedina, 2011.

PISCITELLI, Tathiane. Os desafios da tributação do comércio eletrônico. Revista de Direito Tributário Contemporâneo. v. 1, n. 1. p. 195-216. jul./ago. 2016.

PISTONE, Michele R.; HORN, Michael B.. Disrupting Law School: How disruptive innovation will revolutionize the legal world. Clayton Christensen Institute, mar. 2016. Disponível em: <http://www.christenseninstitute.org/publications/disrupting-law-school/>. Acesso em: 11 maio 2016.

PRADO, Edmir Parada Vasques. Terceirização de Serviços de Tecnologia da Informação em Organizações Brasileiras. Revista de Gestão USP, v. 15, n. 2, São Paulo, p. 99-112, abril/junho 2008.

PRICEWATERHOUSECOOPERS (PwC). How does one tax the cloud? Jan. 2012, p. 111 [3]. Disponível em: <https://www.pwc.com/us/en/state-local-tax/assets/pwc-how-doesone-tax-the-cloud.pdf $>$. Acesso em: 2 ago. 2016.

QUEIROZ, Luís Cesar Souza de. Imposto sobre a Renda: requisitos para uma tributação constitucional. Rio de Janeiro: Forense, 1996.

RAAD, Kees van. Escopo geográfico das regras de distribuição da convenção modelo da OCDE. Direito Tributário Atual. n. 22. São Paulo: Dialética. p. 101-107. 2008.

RAMOS, Pedro. O que é neutralidade da rede? Disponível em:

<http://www.neutralidadedarede.com.br/>. Acesso em: 5 abr. 2016.

REACH, Catherine Sanders. Understanding Basic Elements of Cloud Operation. DePaul Business \& Commercial Law Journal, vol. 12, n. 4, p. 455-469, 2014. Disponível em: < <http://via.library.depaul.edu/bclj/vol12/iss4/2/>. Acesso em: 2 set. 2016.

REDE NACIONAL DE ENSINO E PESQUISA (RNP). "Nossa História". Disponível em: <https://www.rnp.br/institucional/nossa-historia>. Acesso em: 10 abr. 2016.

REIS, Jair Teixeira. Terceirização Trabalhista. Âmbito Jurídico, Rio Grande, VIII, n. 21, mai. 2005. Disponível em: <http://www.ambito-

juridico.com.br/site/index.php?n_link=revista_artigos_leitura\&artigo_id=612>. Acesso em: 2 set. 2016.

RIAA. Facts \& Research. 2017. Disponível em: <https://www.riaa.com/riaa-reports-2016year-end-music-industry-revenues/>. Acesso em: 10 abr. 2017.

RIBEIRO, Ricardo Lodi; ROCHA, Sérgio André (Coords.). Legalidade e Tipicidade no Direito Tributário. São Paulo: Quartier Latin, 2008; ZILVETI, Fernando Aurelio. O ISS e o arrendamento mercantil: a posição atual do STF. Direito Tributário Atual. n. 25. São Paulo: Dialética. 2011. 
RIBEIRO, Ricardo Pereira; VASCONCELLOS, Roberto França. A transferência internacional de tecnologia e sua tributação. Revista de Direito Tributário Internacional. n. 6. São Paulo: Quartier Latin. P. 127-168. ago./2007.

RIGONI, João Marcus de Melo. A Brazilian View on Base Erosion and Profit Shifting: An Alternative Path. Intertax. v. 42, n. 11. p. 730-742. 2014.

ROCHA, Sergio André. A Sujeição Passiva no IRRF de não Residentes. Revista Dialética de Direito Tributário. n. 234. São Paulo: Dialética, p. 128-136. mar./2015. Latin. 2013.

Interpretação dos tratados para evitar a dupla tributação. São Paulo: Quartier

. País tem seu próprio caminho na tributação internacional. Conjur. São Paulo, 3 set. 2013. Disponível em: <http://www.conjur.com.br/2013-set-03/sergio-rochaimportacao-doutrinas-forma-critica>. Acesso em: 2 maio 2017.

. Relação entre o Direito Doméstico e as Convenções para evitar a Dupla Tributação da Renda no Brasil: O Artigo 98 do Código Tributário Nacional. Direito Tributário Atual. n. 29. São Paulo: Dialética. p. 325-350. jan.-jun./2013.

ROCHA, Valdir de Oliveira (Org.). Grandes Questões do Direito Tributária. vol. 10. São Paulo: Dialética, 2006.

ROHRMANN, Carlos A.; CUNHA, Juliana Falci Sousa Rocha. Some Legal Aspects of Cloud Computing Contracts. Journal of International Commercial Law and Technology, vol. 10, n. 1, 2015. Disponível em:

<www.jiclt.com/index.php/jiclt/article/download/230/227>. Acesso em: 2 abr. 2016.

ROMANO, Santi. Fragmentos de un Diccionario Juridico. Buenos Aires: Ediciones Juridicas Europa-America, 1964.

ROSSI, Mariza Delapieve; GUERRA, Marcelo de Assis; BRAGA, José Augusto F.. National Report - Brazil. In: Taxation of Income Derived from Electronic Commerce. Cahiers de Droit Fiscal International. vol 86a. Rotterdam: Kluwer for the International Fiscal Association. 2001.

ROTHMANN, Gerd Willi. Bitributação Internacional. In: Temas fundamentais de direito tributário atual. Belém: CEJUP, 1983.

Ganho de capital obtido na venda de artigos por não residente no Brasil. Revista Internacional de Direito Tributário. vol. 8. Belo Horizonte: Del Rey. p. 241-247. jul.dez./2007.

Problemas de Qualificação na Aplicação das Convenções contra a Bitributação Internacional. Revista Dialética de Direito Tributário. n. 76. São Paulo: Dialética. p. 33 43. jan./2002.

. Tributação Internacional sem Sujeito Passivo: uma Nova Modalidade do Imposto de Renda sobre Ganhos de Capital? In: ROCHA, Valdir de Oliveira (Coord.). Grandes Questões Atuais do Direito Tributário. vol. 10. São Paulo: Dialética, 2006, p. 106-16. 
ROTHMANN, Gerd Willi. Tributação dos serviços importados na legislação doméstica e internacional do Brasil. In: PARISI, Fernanda Drummond.; TÔRRES, Heleno Taveira; MELO, José Eduardo Soares de (Coords.). Estudos de direito tributário em homenagem ao professor Roque Antonio Carrazza. Vol. 2. São Paulo: Malheiros. 2014.

SACCHETTO, Claudio. El Principio de Territorialidad. In: UCKMAR, Victor; ALTAMIRO, Alejandro C.; TÔRRES, Heleno Taveira (Coord.). Impuestos sobre el comercio internacional. Buenos Aires: Editorial Ábaco de Rodolfo Depalma, 2003.

SANTIGAGO, Igor Mauler. Conflito na definição de fonte leva à dupla tributação de rendas passivas. CONJUR. São Paulo, 11 fev. 2015. Disponível em:

<http://www.conjur.com.br/2015-fev-11/consultor-tributario-conflito-definicao-fonte-levadupla-tributacao-rendas-passivas >. Acesso em: 20 abr. 2017.

SANTOS, João Victor Guedes. O critério da fonte num cenário globalizado: imprecisões conceituais e o paradigmático caso Agassi. Revista de Direito Tributário. n. 109/110. São Paulo: Malheiros. p. 242-258. 2010.

SANTOS, Manoel Joaquim Pereira dos. A Proteção Autoral de Programas de Computador. Rio de Janeiro: Lumen Juris, 2008.

Software - Acesso ao código-fonte e transferência de tecnologia. Revista de

Direito de Informática e Telecomunicações. n. 11. Belo Horizonte: Fórum. p. 67-80. jul.dez./2011.

SANTOS, Ramon Tomazela. A Autonomia do Direito Tributário e os Conceitos de Direito Privado: a Incidência do IOF/Crédito sobre os Contratos de Mútuo de Recursos

Financeiros. Revista Dialética de Direito Tributário. n. 224. São Paulo: Dialética, p. 132-149, mai. 2014.

- O ganho de capital auferido por não residentes - a alienação indireta de participação societária e a alienação de American Depositary Receipts - análise do artigo 26 da Lei n. 10833/2003. Revista Dialética de Direito Tributário. São Paulo: Dialética. n. 235. p. 128-149. abr/2015.

. O Princípio da Universalidade na Tributação da Renda: Análise acerca da Possibilidade de Atribuição de Tratamento Jurídico-Tributário Distinto a Determinados Tipos de Rendimentos Auferidos pelas Pessoas Físicas. Direito Tributário Atual. n. 28. São Paulo: Dialética. p. 264-294. 2012.

SARATT, Newton et. al. Quarteirização: redefinindo a terceirização. v. 1. Porto Alegre: Badejo, 2000.

SASSEVILLE, Jacques. The future of the treaty rules for taxing business profits. In: 2000 World Tax Conference: Taxes Without Borders. Toronto: Canadian Tax Foundation, 2000.

SAUER, Rich. Conquistando Confiança e Compliance na Nuvem. International In-house Counsel Journal. vol. 09. n. 36. 2016. 
SAVELBERGH, J.W. Taxation issues of cross-border transfers of computer software. Intertax. n. 5. p. 104-109. 1986.

SCHAEFER, Barrett. International Taxation of Electronic Commerce Income: A Proposal to Utilize Software Agents for Source-Based Taxation. Santa Clara High Technology Law Journal. vol. 16. n. 1. p. 111-140. Jan./2000.

SCHAUER, Frederick. Playing by the rules. Oxford: Clarendon Press, 2002.

SCHINDEL, Ángel. Los criterios de la fuente e de la residência. In: PISTONE, Pasquale; TÔRRES, Heleno Taveira. Estudios de derecho tributario constitucional e internacional. Buenos Aires: Editorial Ábaco de Rodolfo Depalma.

SCHINDEL, Ángel; ATCHABAHIAN, Adolfo. General Report. In: Source and residence: new configuration of their principles. Cahiers de Droit Fiscal International. vol. 90a. Rotterdam: Kluwer for the International Fiscal Association. 2005.

SCHON, Wolfgang. International Tax Coordination for a Second-Best World (Part I). World Tax Journal. vol. 1. n. 1. out./2009.

SCHOUERI, Luís Eduardo. Direito Tributário. 3. ed. São Paulo: Saraiva, 2013.

Imposto de Renda e o Comércio Eletrônico. In: et al (Org.). Internet: o direito na era virtual. São Paulo: Lacaz Martins, Halembeck, Pereira Neto, Gurevich \& Schoueri Advogados, 2000.

. O Mito do Lucro Real na Passagem da Disponibilidade Jurídica para a Disponibilidade Econômica. In: MOSQUERA, Roberto Quiroga. Controvérsias jurídicocontábeis (aproximações e distanciamentos). São Paulo: Dialética, 2010.

Planejamento Fiscal Através de Acordos de Bitributação: Treaty Shopping. São Paulo: Revista dos Tribunais, 1995.

. Princípios no Direito Tributário Internacional: Territorialidade, Fonte e Universalidade. In: FERRAZ, Roberto (Coord.). Princípios e Limites da Tributação. São Paulo: Quartier Latin, 2005.

. Regras de Residência Fiscal da Pessoa Física no Direito Comparado e no Direito Brasileiro. Revista Tributária das Américas. Vol. 5. São Paulo: Revista dos Tribunais. jan.-jun./2012.

. Solidariedade, Domicílio e Capacidade Contributiva. In: MARTINS, Ives Gandra da Silva; NASCIMENTO, Carlos Valder do; MARTINS, Rogério Gandra da Silva. Tratado de Direito Tributário. São Paulo: Saraiva, 2011.

. Tax Sparing: uma Reconsideração da Reconsideração. Direito Tributário Atual. n. 26. São Paulo: Dialética. p. 93-108. 2011.

. Tratados e convenções internacionais sobre tributação. Direito Tributário Atual. n. 17. São Paulo: Dialética. 2003. 
SCHOUERI, Luís Eduardo. Tributação e Cooperação Internacional. Revista Fórum de Direito Tributário. ano 2. n. 7. jan./fev. 2004, cópia da versão digital, s/n página.

SCHOUERI, Luís Eduardo; ANDRADE JUNIOR, Luiz Carlos de; VIANA, Matheus Cherulli Alcantara. A Tributação das Prestações Decorrentes de Contratos de "Engineering, Procurement and Conscruction/EPC". In: BARRETO, Aires Fernandino (Coord.). Direito Tributário Contemporâneo - Estudos em homenagem a Geraldo Ataliba. São Paulo: Malheiros, 2011.

SCHOUERI, Luís Eduardo; CEZAROTI, Guilherme. A Cide-royalties e as Remessas por Licença de Distribuição e Comercialização de Programas de Computador. Revista Dialética de Direito Tributário. n. 130. São Paulo: Dialética. jul./2006.

SCHOUERI, Luís Eduardo; GUNTHER, Oliver-Christoph. A Subsidiária/Filial (Subsidiary) como Estabelecimento Permanente. Revista de Direito Tributário Internacional. ano 6. n. 16. São Paulo: Quartier Latin. p. 103-118. jul./2011.

SCHUARTZ, Luiz Fernando. Mercados de Alta Tecnologia: crise anunciada do direito da concorrência? In: GRECO, Marco Aurélio; MARTINS, Ives Gandra da Silva. Direito e Internet: relações jurídicas na sociedade informatiza. São Paulo: Revista dos Tribunais, 2001.

SCHUBERT, Lutz; JEFFERY, Keith (Ed.). Advances in Clouds: research in future cloud computing. Expert Group Report. Public Version 1.0. European Commission, 2012, p. 18-22. Disponível em: <http://cordis.europa.eu/fp7/ict/ssai/docs/future-cc-2mayfinalreport-experts.pdf $>$. Acesso em: 3 jun. 2016.

SCHUNK, Caio. A Tributação do não Residente pelo Imposto de Renda no Brasil e os Rendimentos Provenientes de Imóvel Situado no Exterior. Direito Tributário Atual. $n$. 27. São Paulo: Dialética.2012.

SCHWARTZ, Paul M. Information privacy in the cloud. University of Pennsylvania Law Review, vol. 161, n. 1623, 2013, p. 1623-1662. Disponível em:

<http://scholarship.law.upenn.edu/cgi/viewcontent.cgi?article=1024\&context=penn_law_r eview>. Acesso em: 2 abr. 2016.

SCREPANTE, Mirna S. Cross-Border Software Transactions from a Technology Importing Country Perspective: The Case of the Argentina-Germany Income and Capital Tax Treaty (1978). Bulletin for International Taxation. set./2013

SECRETARIA DA RECEITA FEDERAL DO BRASIL. Solução de Divergência COSIT n. 11. Brasília, DF, 28 de abril de 2011 (g. n). Disponível em:

$<$ http://normas.receita.fazenda.gov.br/sijut2consulta/link.action?visao=anotado\&idAto $=60$ 550>. Acesso em: 10 out. 2016).

SELIGMAN, Edwin. Double Taxation and International Fiscal Cooperation. Nova Iorque: Macmillian, 1928.

SHAKOW, David. The Taxation of Cloud Computing and Digital Content. Tax Notes. v. 140. n. 4. jul. 2013. 
SILVA, De Plácido e. Vocabulário Jurídico. 18. ed. Rio de Janeiro: Forense, 2001.

SILVA, Emerson Drigo. Aspecto Espacial da Tributação dos Serviços Prestados por Meio da Internet. Dissertação (Mestrado em Direito) - Faculdade de Direito da Universidade de São Paulo, São Paulo, 2004.

SILVA, Mauro José. Da competição à cooperação tributária: aspectos jurídicos da promoção do desenvolvimento nacional num cenário internacionalizado. Tese (Doutorado em Direito): Universidade de São Paulo, São Paulo, 2009.

SILVEIRA, Rodrigo Maitto da. Aplicação dos tratados internacionais contra a bitributação: qualificação de partnership joint ventures. São Paulo: Quartier Latin, 2006.

Caso Pierre Boulez: conflito de qualificação de rendimentos à luz do tratado EUA-Alemanha - Royalties versus Prestação de Serviços. In: CASTRO, Leonardo Freitas de Moraes e (Coord.). Tributação Internacional: Análise de Casos. vol. 2. São Paulo: MP. 20015.

O Escopo Pessoal dos Acordos Internacionais Contra a Bitributação. São Paulo: Quartier Latin, 2016.

SOOS, Piroska E. The Origins of Taxation at Source in England. Amsterdam, The Netherlands: IBFD Publications, 1997.

SPRAGUE, Gary D.; BOYLE, Michael P.. General Report. In: Taxation of Income Derived from Electronic Commerce. Cahiers de Droit Fiscal International. vol. 86a. Rotterdam: Kluwer for the International Fiscal Association. p. 21-63. 2001.

STEPANEK, Marcia. Micro-Multinationals Rising. Stanford Social Innovation Review, 14 mai. 2010. Disponível em: <http://ssir.org/articles/entry/micro-multinationals_rising>. Acesso em: 13 mar. 2016.

SULLIVAN, Martin. Tax Challenges for the Uber Economy. Forbes: Taxes, 14 jul. 2015. Disponível em: <http://www.forbes.com/sites/taxanalysts/2015/07/14/tax-challenges-forthe-uber-economy/print/ $>$.

SUNDFELD, Carlos Ari et al. Seminário sobre o Regime Tributário de Modernos Institutos de Direito Empresarial - "Leasing" e "Merchandising". Revista de Direito Tributário. n. 38. p. 184-208. out.-dez. 1986.

SUNDFELD, Carlos Ari; ROSILHO, André. A governança não estatal da internet e o direito brasileiro. Revista de Direito Administrativo, Rio de Janeiro, v. 270, p. 41-79, set./dez. 2015.

TADMORE, Niv. Aspects of Electronic Commerce Taxation in Australia. Bulletin for International Taxation. vol. 57. n. 8. p. 422-430. ago/set./2003. 
TADMORE, Niv. Source Taxation of Cross-Border Intellectual Supplies - Concepts, History and Evolution into the Digital Age. Bulletin for International Taxation. vol. 61. n. 1. jan./2007.

TAKANO, Caio Augusto. Conflitos de Competência Tributária entre o ISS e o ICMS: a tributação das "operações mistas" e a evolução da jurisprudência. Revista de Direito Tributário. n. 122. São Paulo: Malheiros. p. 103-112. jan. 2015.

TAKEDA, Nara Cristina. O Conceito de "Estabelecimento Permanente" e o Comércio Eletrônico - Reflexões Frente ao Modelo de Convenção da OCDE e à Legislação Pátria". Dissertação (Mestrado em Direito Econômico e Financeiro) - Faculdade de Direito, Universidade de São Paulo, São Paulo, 2005.

TANZI, Vito. Taxation in an Integrating World. Washington: Brookings Institution, 1994.

TAURION, Cezar. Cloud Computing. Rio de Janeiro: Brasport, 2009.

TAX Annex to the St. Petersburg G20 Leader's Declaration, setembro de 2013. Disponível em: <https://www.oecd.org/g20/summits/saint-petersburg/Tax-Annex-St-Petersburg-G20Leaders-Declaration.pdf>. Acesso em: 5 abr. 2016.

TCHIKAYA, Blaise. Le droit international des télécommunications. Paris: PUF, 1998.

TEIJEIRO, Guillermo O. The BEPS Project Lacks Comprehensive Definition on the Taxation of Digital Economy in Market Jurisdictions Disponível em:

$<$ http://kluwertaxblog.com/2015/10/24/the-beps-project-lacks-comprehensive-definitionon-the-taxation-of-digital-economy-in-market-jurisdictions/>. Acesso em: 4 dez. 2016.

TEIXEIRA, Alessandra Machado Brandão. A residência das pessoas jurídicas no Direito Tributário brasileiro: art. 75 do Código Civil. In: TÔRRES, Heleno Taveira (Coord.). Direito Tributário Internacional aplicado. vol. V. São Paulo: Quartier Latin, 2008.

TELECOMMUNICATIONS Services. Disponível em: <https://www.wto.org/english/tratop_e/serv_e/telecom_e/telecom_e.htm>. Acesso em: $1^{\underline{o}}$ mar. 2016.

TEODOROVICZ, Jeferson. Autonomia do Direito Tributário: revisitando a Polêmica do Uso dos Conceitos de Direito Privado em Direito Tributário. Direito Tributário Atual, n. 30. São Paulo: Dialética, 2014.

TESHEINER, José Maria. Jurisdição territorial nos Estados Unidos da América do Norte e Competência Internacional e de Foro no Brasil. Revista Eletrônica de Direito Processual - REDP. vol. XIII. UERJ. p. 259- 273. Disponível em: <www.epublicacoes.uerj.br/index.php/redp/article/download/11921/9334>. Acesso em: $1^{\stackrel{0}{ }}$ fev. 2017. 
THIEDA, Christopher. Cloud Computing Definitions and Technical Considerations. In: MARTINS, James P.; CENDROWSKI, Harry. Cloud Computing: Basics of Technologies and Applications. New Jersey: John Wiley \& Sons. 2014.

TILBERY, Henry. O novo imposto de renda no Brasil. São Paulo: IOB, 1989.

TILLINGHAST, David. The Impact of the Internet on the Taxation of International Transactions. Bulletin for International Fiscal Documentation, vol. 50, p. 524-526, 1996.

TÔRRES, Heleno Taveira. A Tributação dos Não-Residentes no Brasil: O Regime Fiscal dos Dividendos, Juros, Royalties e Capital Gains. In: UCKMAR, Victor (Coord.). Corso di Diritto Tributario Internazionale. Pádua: CEDAM, 1999.

Direito tributário e direito privado: autonomia privada, simulação, elusão tributária. São Paulo: Revista dos Tribunais, 2003.

Pluritributação internacional sobre a renda das empresas: tratamento unilateral, bilateral e comunitário. São Paulo: RT, 1997.

. Princípio da Territorialidade e Tributação de Não-Residentes no Brasil. Prestações de Serviços no Exterior. Fonte de Produção e Fonte de Pagamento. In: Direito

Tributário Internacional Aplicado. São Paulo: Quartier Latin, 2003.

TORRES, Ricardo Lobo. A Chamada “Interpretação Econômica do Direito Tributário", a Lei Complementar 104 e os Limites Atuais do Planejamento Tributário. In: ROCHA, Valdir de Oliveira. O Planejamento Tributário e a Lei Complementar 104. São Paulo: Dialética, 2001.

. Normas de interpretação e integração do Direito Tributário. 4 ed. Rio de Janeiro: Renovar, 2006.

TROTABAS, Louis. Ensaio sobre o Direito Fiscal. Revista de Direito Administrativo. v. 26. Rio de Janeiro: Fundação Getúlio Vargas. p. 34-59. 1951.

UCHÔA Filho, Sérgio Papini de Mendonça. “Análise da tributação internacional de rendimentos dos contratos de patrocínio de esportistas: um novo conceito de fonte?". In: CASTRO, Leonardo Freitas de Moraes e [Org.]. Tributação Internacional: análise de casos. São Paulo: MP, 2010.

UCKMAR, Victor et al. Manual de Direito Tributário Internacional. São Paulo: Dialética, 2012.

UNCITRAL (United Nations Comission on International Trade Law). The Model Law on Electronic Commerce (1996). Disponível em:

<http://www.uncitral.org/uncitral/en/uncitral_texts/electronic_commerce/1996Model.html>. Acesso em: 9 set. 2016. 
UNCTAD (United Nations Conference on Trade and Development). Information Economy Report 2013: The Cloud Economy and Developing Countries. Switzerland: United Nations Publication, 2013, p. 44-49. Disponível em: <http://unctad.org/en/PublicationsLibrary/ier2013_en.pdf>. Acesso em: 2 jun. 2016.

UNITED NATIONS (United Nations). Intersessional Panel of the Commission on Science and Technology for Development (CSTD). The mapping of international Internet public policy issues. Geneva, Switzerland, 26-28 nov. 2014, p. 14._Disponível em: $<$ http://unctad.org/meetings/en/SessionalDocuments/CSTD_2014_Mapping_Internet_en.p df >. Acesso em: 2 abr. 2016.

UTUMI, Ana Cláudia Akie. O Regime Tributário Brasileiro do Imposto sobre a Renda de Não-Residentes. A Fonte como critério de conexão. Tese (Doutorado em Direito): Universidade de São Paulo, São Paulo, 2006.

VAN ALSTYNE, Marshall W. et al. Pipelines, Plataforms, and the New Rules of Strategy. Harvard Business Review, 01 de abril de 2016. Disponível em: <https://hbr.org/2016/04/pipelines-platforms-and-the-new-rules-of-strategy>. Acesso em: 11 abr. 2016.

VAN WEEGHEL, Stef. The Improper Use of Tax Treaties - With Particular Reference to the Netherlands and the United States. London: Kluwer Law, 1998.

VANONI, Ezio. Natureza e interpretação das leis tributárias. Rio de Janeiro: Edições Financeiras.

VARELA, João de Matos Antunes. Contratos Mistos. Boletim da Faculdade de Direito da Universidade de Coimbra. Vol. XLIV, Coimbra, 1968.

. Das Obrigações em geral. vol. 1. 10. ed. Coimbra: Almedina, 2000.

Direito das Obrigações. vol. 2. Rio de Janeiro: Forense, 1978.

VASCONCELLOS, Roberto França de. Aspectos Econômicos dos Tratados Internacionais em Matéria Tributária. Revista de Direito Tributário Internacional, Ano 1, n. 1. São Paulo: Quartier Latin, p. 147-191. 2005.

. Histórico dos Princípios de Tributação das Atividades Transnacionais. Revista Tributária das Américas. ano 2. vol. 4. jul.-dez./2011.

. Os Desafios da Tributação de Operações Internacionais na Economia Digital. In: SCHOUERI, Luís Eduardo; BIANCO, João Francisco (Coords.). Estudos de Direito Tributário em Homenagem ao Prof. Gerd Willi Rothmann. São Paulo: Quartier Latin, 2016.

. Tributação do Comércio Eletrônico Internacional. Tese (Doutorado em Direito Econômico e Financeiro) - Faculdade de Direito, Universidade de São Paulo, São Paulo, 2002. 
VASCONCELLOS, Roberto França de; RIBEIRO, Ricardo Pereira. Aspectos Tributários da Transferência de Tecnologia. In: DE SANTI, Eurico Marcos Diniz; ZILVETI, Fernando Aurelio (Coords.). Direito Tributário - Tributação Internacional. São Paulo: Saraiva, 2007.

VELLOSO, Andrei Pitten. Conceitos e competências tributárias. São Paulo: Dialética, 2005.

VICENTE, Dário Moura. Direito de Autor e Comércio Electrónico: Aspectos Internacionais. In: WACHOWICZ, Marcos; MORENO, Guillermo Palao (Coords.). Propriedade Intelectual: Inovação e Conhecimento. Curitiba: Juruá, 2010.

VIEGAS, Juliana L. B. Aspectos legais da contratação na área de propriedade industrial. In: SANTOS, Manoel Joaquim Pereira dos; JABUR, Wilson Pinheiro (Coords.).

Contratos de propriedade industrial e novas tecnologias. São Paulo: Saraiva. 2007.

VIEIRA, José Roberto. O papel da lei complementar no estabelecimento das fronteiras IPI X ISS: óculos para macacos. In: Moreira, André Mendes et al. X Congresso Nacional de Estudos Tributários. Sistema Tributário Brasileiro e as Relações Internacionais. São Paulo: Noeses, 2013.

VOGEL, Klaus. Double Tax Treaties and Their Interpretation. International Tax Law \& Business Law. vol. 4. n. 1. p. 1-85. 1986.

. Problemas na Interpretação de Acordos de Bitributação. In: SCHOUERI, Luís Eduardo (Coord.). Direito Tributário - Homenagem a Alcides Jorge Costa. Vol. II. São Paulo:Quartier Latin, 2003.

The Influence of the OECD Commentaries on Treaty Interpretation. Bulletin Tax Treaty Monitor. Amsterdam: IBFD. p. 612-619. dez./2000.

World-wide vs source taxation of income - A review and reevaluation of arguments [Part I]. Intertax. n. 216. p. 216-229. 1988.

WACHOWICZ, Marcos. O programa de computador como objeto do Direito Informático. Conjur. São Paulo. 14 abr. 2003. Disponível em: <http://www.conjur.com.br/2003-abr14/software_objeto_direito_informatico>. Acesso em: 21 abr. 2017.

WEF. The Global Information Technology Report 2016. Geneva, jul. 2016. Disponível em: 〈https://www.weforum.org/reports/the-global-information-technology-report-2016/>. Acesso em: 2 jun. 2016.

WEIKERSHEIMER, Deana. Comercialização de software no Brasil: uma questão legal a ser avaliada. 2. ed. Rio de Janeiro: Forense, 2000.

WESTIN, Richard. International Taxation of Electronic Commmerce. The Hague: Kluwer Law International, 2000. 
WHATSAPP é 'pirataria pura', afirma presidente da Vivo. Folha de São Paulo, São Paulo, 7 ago. 2015. Mercado. Disponível em:

<http://www1.folha.uol.com.br/mercado/2015/08/1666187-whatsapp-e-pirataria-puraafirma-presidente-da-vivo.shtml>. Acesso em: 11 abr. 2016).

WICHMAN, Michael. The Taxation of Services: is the Permanent Establishment the Appropriate Threshold? Bulletin for International Taxation. vol. 58. n. 5. mai./2004.

WINKLER, Vic. Computação em Nuvem: as questões de segurança de nuvem. TechNet Magazine. nov. 2011. Disponível em: <https://technet.microsoft.com/ptbr/library/hh536219.aspx>. Acesso em: 23 set. 2016.

WIPO. WIPO Intellectual Property Handbook: Policy, Law and Use. Geneva: WIPO Publication, 2004. Disponível em: <http://www.wipo.int/about-ip/en/iprm/>. Acesso em: 5 abr. 2016.

WORLD BANK. World Development Report 2016: Digital Dividends. Washington, D.C. 2016. Disponível em: <http://www.worldbank.org/en/publication/wdr2016>. Acesso em: 8 out. 2016.

XAVIER, Alberto. A Tributação da Prestação Internacional de Serviços, em Especial de Serviços Técnicos e de Assistência Técnica. Revista Dialética de Direito Tributário. $n$. 235. São Paulo: Dialética. p. 7-28. abr./2015.

Da Tributação dos Rendimentos Pagos a Titulares de Data Center Residentes no Exterior. Revista Dialética de Direito Tributário. n. 234. São Paulo, p. 7-14. 2015.

Direito Tributário Internacional do Brasil. 8. ed. São Paulo: Forense, 2015. 1981.

Manual de Direito Fiscal I. Lisboa: Manuais da Faculdade de Direito de Lisboa,

. O Imposto de Renda na Fonte e os Serviços Internacionais - Análise de um Caso de Equivocada Interpretação dos arts. 7 e 21 dos Tratados. Revista Dialética de Direito Tributário. n. 49. p. 7-17. out./1999.

XAVIER, Manoela Floret Silva. A atribuição de lucros em estabelecimentos permanentes. In: TÔRRES, Heleno Taveira (Coord.). Direito Tributário Internacional Aplicado. São Paulo: Quartier Latin, 2007.

YAMASHITA, Douglas. Licenciamento de Software no Brasil: Novas Tendências Tributárias. Revista Dialética de Direito Tributário. n. 141. São Paulo: Dialética. p. 6268. jun./2007.

YIGITBASIOGLU, Ogan M.; MACKENZIE, Kim; LOW, Rouhshi. Cloud Computing: How does it differ from IT outsourcing and what are the implications for practice and research? The International Journal of Digital Accounting Research, vol. 13, p. 99 $121,2013$. 
YOO, Christopher. Cloud Computing: Architectural and Policy Implications. University of Pennsylvania Law School, Institute for Law \& Economic Research Paper n. 11-15, jan. 2011.

YOUSEFF, Lamia; BUTRICO, Maria; SILVA, Dilma da. Toward a Unified Ontology of Cloud Computing, Grid Computing Environments Workshop, 2008. Disponível em: <smestorage.com/files/8f047da34a2d3a3528136ba8b59a465d.pdf>. Acesso em: 3 jun. 2016.

ZAGREBELSKY, Gustavo. El derecho dúctil. Madrid: Trotta, 2009.

ZANGRANDO, Carlos Henrique da Silva. Curso de Direito do Trabalho - direito individual do trabalho, Tomo 2. São Paulo: LTr, 2008.

ZILVETI, Fernando Aurelio. A Tributação sobre o Comércio Eletrônico - O Caso Amazon. Direito Tributário Atual. n. 26. São Paulo: Dialética, p. 231-245, 2011.

. Obrigação tributária - fato gerador e tipo. São Paulo: Quartier Latin, 2009.

Princípios de Direito Tributário e a Capacidade Contributiva. São Paulo: Quartier Latin, 2004.

ZIMMECK, Sebastian. The Information Privacy Law of Web Applications and Cloud Computing. Santa Clara High Technology Law Journal, vol. 29, n. 3, p. 451-487, abr. 2013. Disponível em:

<http://digitalcommons.law.scu.edu/cgi/viewcontent.cgi article $=1564 \&$ context $=$ chtlj $>$. Acesso em: 21 set. 2016.

ZYSMAN, John; KENNEY, Martin. The Next Phase in the Digital Revolution: Platforms, Abundant Computing; Growth and Employment. Berkeley Roundtable on International Economy - BRIE Working Paper n. 2016-3, ago. 2016. Disponível em:

<http://www.brie.berkeley.edu/wp-content/uploads/2015/02/BRIE-working-paper-201633.pdf>. Acesso em: 13 set. 2016. 